\title{
Influence of Propeller Overlap on Large Scale Tandem UAV Performance
}

\author{
Adrian B. Weishäupl ${ }^{\mathrm{a}}$, Stephen D. Prior ${ }^{\mathrm{a}}$ \\ ${ }^{a}$ Aeronautics, Astronautics and Computational Engineering, Faculty of Engineering and Physical Sciences, University of \\ Southampton, Bolderwood Campus, Southampton, SO16 7QF, United Kingdom \\ E-mail:aw6g15@soton.ac.uk
}

\begin{abstract}
This paper investigates the interference that arises from overlapping UAV propellers during hovering flight. The tests have been conducted on 28 " x 8.4" Ultralight Carbon Fibre propellers using a bespoke mount and the RCBenchmark Series 1780 dynamometer at various degrees of overlap (z/D) and vertical separation (d/D). A great deal of confusion regarding the losses that are associated with mounting propellers in a coaxial configuration are reported in the literature, with a summary of historical tandem helicopters having been conducted. The results highlight a region of beneficial overlap (0-20\%), which has the potential to be advantageous to a wide range of UAVs.
\end{abstract}

Keywords: Propeller, Efficiency, Tandem, Overlap, UAV, Interference

\begin{tabular}{|c|c|}
\hline \multicolumn{2}{|c|}{ Nomenclature } \\
\hline c & Chord (m) \\
\hline $\mathrm{d}$ & Stagger $(\mathrm{m})$ \\
\hline $\mathrm{k}$ & Induced Power Factor \\
\hline $\mathrm{n}$ & Revolutions per Second $\left(\mathrm{s}^{-1}\right)$ \\
\hline $\mathrm{r}$ & Section Radius (m) \\
\hline s & Slant Line Distance Between Rotors (m) \\
\hline $\mathrm{z}$ & Propeller Plane Separation (Gap) (m) \\
\hline $\mathrm{A}_{\mathrm{O}}$ & Area Overlap $\left(\mathrm{m}^{2}\right)$ \\
\hline $\mathrm{C}_{\mathrm{D} 0}$ & Profile Drag \\
\hline $\mathrm{C}_{\mathrm{P}}$ & Coefficient of Power \\
\hline $\mathrm{C}_{\mathrm{T}}$ & Coefficient of Thrust \\
\hline $\mathrm{D}$ & Propeller Diameter (m) \\
\hline $\mathrm{P}_{\mathrm{i}}$ & Induced Power $(\mathrm{W})$ \\
\hline Q & Torque $(\mathrm{Nm})$ \\
\hline $\mathrm{R}$ & Radius (d/2) (m) \\
\hline $\mathrm{R}_{\mathrm{e}}$ & Reynolds Number \\
\hline $\mathrm{T}$ & Thrust (N) \\
\hline $\mathrm{V}_{\mathrm{i}}$ & Induced Velocity $\left(\mathrm{ms}^{-1}\right)$ \\
\hline$\eta$ & Efficiency \\
\hline$\rho$ & Density $\left(\mathrm{kgm}^{-3}\right)$ \\
\hline
\end{tabular}

\section{Introduction and Historical Perspective on Tandem Rotorcraft}

The origins of tandem rotorcraft can be traced back to the early pioneers of flight: Cornu, Breguet, de Bothezat, Ehmichen and others. Of particular note, is the Russian aeronautical engineer and émigré to Belgium, Nicolas Florine who in December 1926 patented his 'An Improved Helicopter' [1] (Fig. 1.). This early helicopter was the first to successfully fly in a tandem configuration, with two rotors rotating in the same direction (unlike later iterations). To counteract the yaw effect,
Florine canted the forward and aft rotors by a $7 \mathrm{deg}$ angle from the vertical, in opposite directions (starboard and port). His early prototypes 'Type I' and 'Type II', resulted in the flight duration record of 9 minutes and 58 seconds in October 1933 [2].

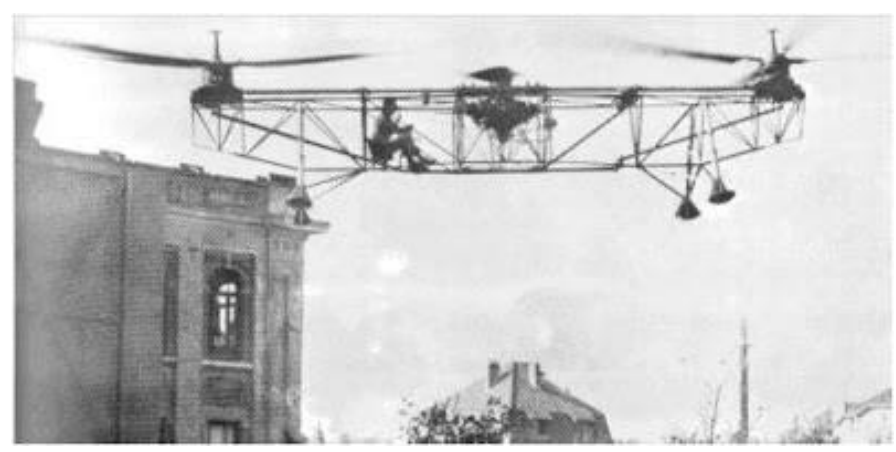

Fig. 1. The Florine Tandem Helicopter

Frank Piasecki, an American aeronautical engineer of Polish descent, continued where Florine (hampered by the War) left off; founding the PV Engineering Forum company in 1940, and using WWII to develop his range of tandem rotorcraft with the financial support and input from the US government and armed forces. The key improvements introduced by Piasecki, were the use of larger overlapping rotors (up to 34\%), which rotated in opposite directions (thus cancelling yaw), and therefore needed to be indexed and offset (the aft rotor positioned above the forward rotor). These key features relate to the $d / D$ ratio (overlap) and the $\mathrm{z} / \mathrm{D}$ ratio (offset) ( 0.15 for the $\mathrm{CH}-47$ [3]), sometimes referred to as Gap and Stagger. The Piasecki Helicopter Corporation eventually led to the Vertol corporation, which was later acquired by Boeing. Though various competitor tandem helicopter systems were developed in the US, Russia, UK and China throughout the period 195070, with some success (Piasecki YH-16A, Bristol Belvedere and 
Bell HSL), none of these could compete with the highly capable Boeing Sea Knight CH-46 and Chinook CH-47, of which over 1200 aircraft have been built over six generations (A to F). The longevity of this aircraft is impressive, with the latest generation planned to be in service beyond 2060, over 100 years after entering service.

One of the key aerodynamic features, that of rotor overlap, may be more due to mechanical constraints rather than aerodynamic optimization. An early DTIC (NACA) report states that: "A 33-percent maximum overlap has historically been found to ensure good blade clearance for a 3-bladed rotor..." (Wax, et al, 1966) [13].

Observation of the figure showing the Disk Loading (DL) vs Power Loading (PL) (Fig. 2.) shows a clear linear relationship, $\mathrm{DL}=1 / 8 \times \mathrm{PL}$. The graph of rotor overlap shows the development of ever larger systems, no doubt driven by the requirements of the military customer wishing to carry more payload (personnel and equipment). Only Piasecki and Boeing seem to have pushed this to the absolute physical limit with 3bladed rotors.

The Overlap vs Maximum Take-Off Mass (MTOM) figure (Fig. 3.) shows the variability of this feature across different manufacturers. It would appear that in order to meet the increasing customer demand for payload, manufacturers began to increase the rotor overlap in order to reduce the aircraft length to a manageable size. Increasing the number of rotor blades from two (Bell), to three (Piasecki [4], Boeing Vertol) and four (Bristol, Yakovlev [5]), in order to improve the lift capability had its own impact on maximum overlap capacity, due to the need for rotor indexing.

With the rising in use of Unmanned Aerial Vehicles (UAVs) in recent years [6], the demand for small propellers has increased substantially. However, the efficiency of these small propellers is far less than the efficiency achieved in large propellers [7]. Often the efficiency is in the range of $30-65 \%$, with a few examples reaching above $70 \%$ [8]. This is considerably below the efficiencies of a typical Lithium ion battery at $99 \%$ [9] or a brushless DC motor at above $80 \%$ [10] and severely reduces the total efficiency of the power-train (see Eq. (1)).

$$
\eta_{\text {power-train }}=\eta_{\text {battery }} \times \eta_{\text {esc }} \times \eta_{\text {motor }} \times \eta_{\text {propeller }}
$$

where $\eta$ is the efficiency of the individual components in the drive-train.

This comparative inefficiency produces a large reduction of available thrust and as a result, the endurance of

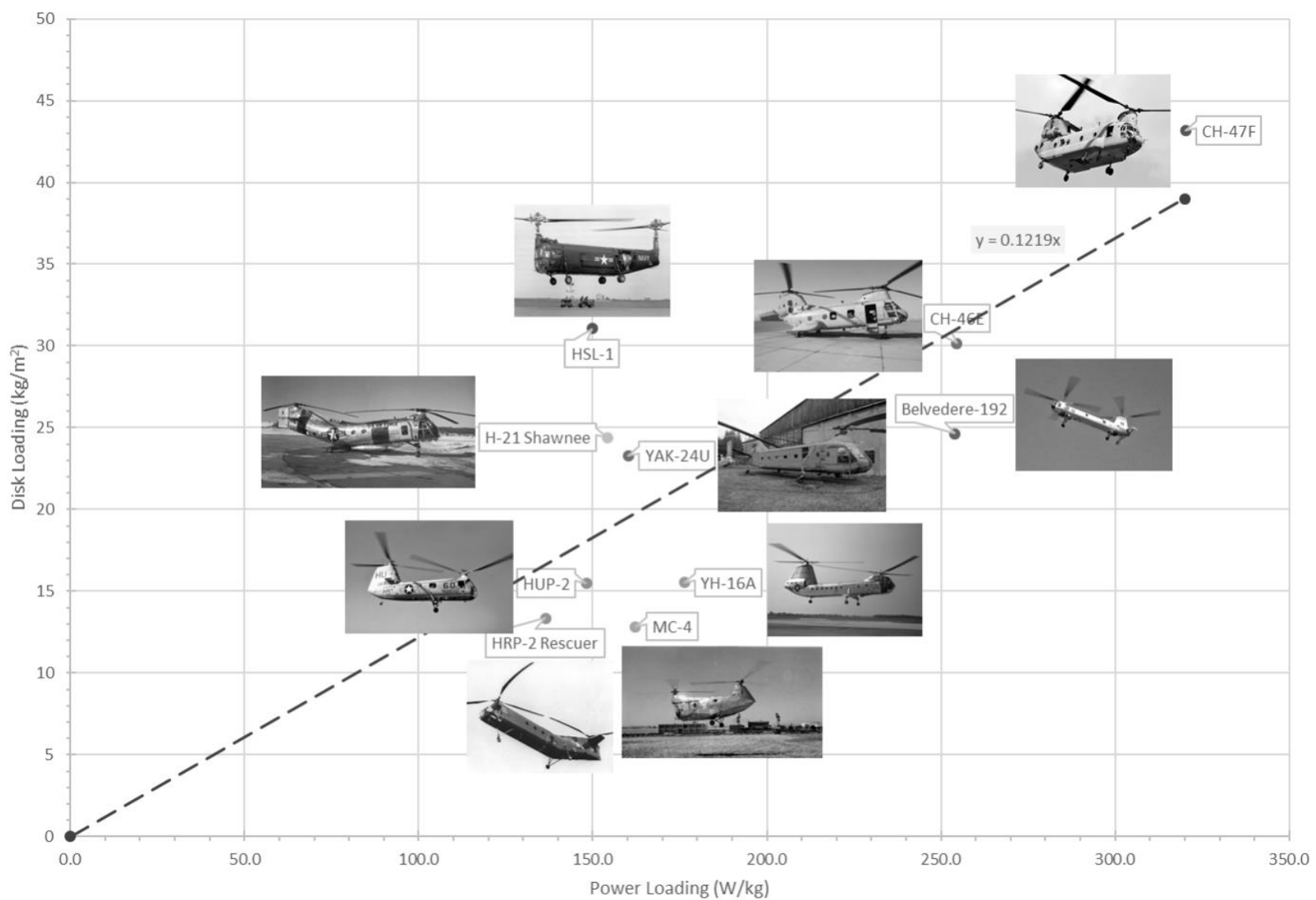

Fig. 2. Disk Loading vs Power Loading for a range of historic tandem helicopters 


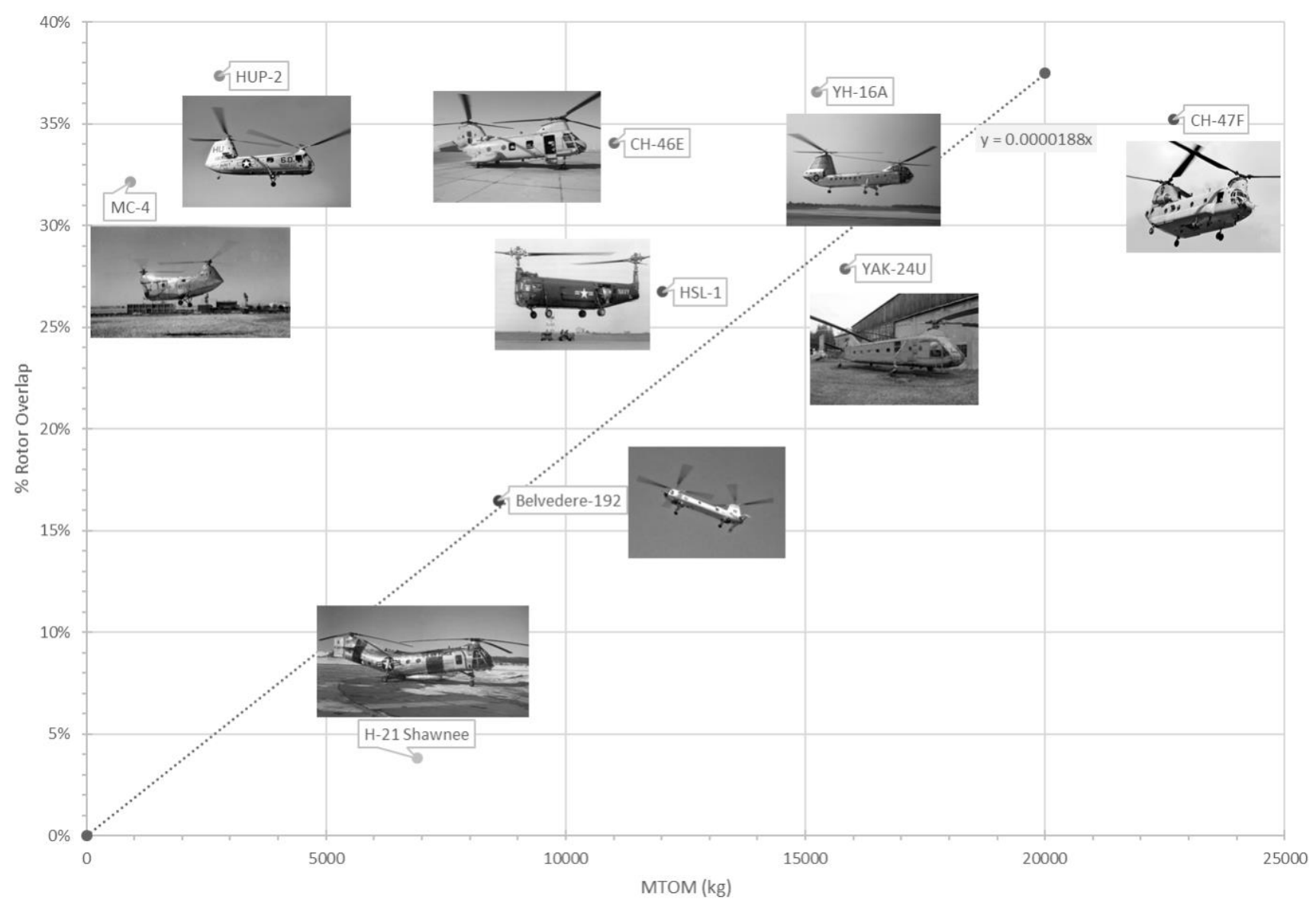

Fig. 3. Percentage Rotor Overlap vs Maximum Take-Off Mass for a range of historic tandem helicopters

UAVs suffers. In light of the scarce existing research, there is considerable scope for development to address and overcome these challenges.

Propellers have been around since the early days of flight and large propellers are well developed [11]. Current multi-rotor configurations often have either co-axial or independent propellers. This article investigates the effect of propeller configuration on the efficiency of a propeller setup with various degrees of overlap. Tests by the National Advisory Committee for Aeronautics (NACA) have found that, for large overlapping rotors, a region of beneficial influence may exist in hover [12]. This, however, was dismissed as likely not providing any beneficial properties during forward flight.

An early (1966) computational model developed for heavy lifting helicopters stated that the allowable rotor overlap is from 0 to $35 \%$ for tandem rotors [13]. As a result, a 32\% rotor overlap was recommended by the Vertical Lift Division (VERTOL) of the Boeing Company to the U.S. Army Aviation Materiel Laboratories (USAAVLABS) for the design of a tandem rotor heavy lift helicopter [14]. As a result of the research conducted by VERTOL, the Boeing CH-46 Sea Knight and $\mathrm{CH}-47$ Chinook were developed and had a $34 \%$ propeller overlap for 3 bladed propellers [15]. With the early $\mathrm{CH}-47$ Chinooks, the rotor planes were tilted at $9^{\circ}$ (forward rotor) and $4^{\circ}$ (aft rotor). The current Chinook, the $\mathrm{CH}-47 \mathrm{D}$, has tilt angles at around $5.5^{\circ}$ for the forward rotor and $4.5^{\circ}$ for the aft rotor. This is designed for a number of reasons: for longitudinal stability during low airspeed maneuvering such as during landing [16] and so that the rotor axes are tilted forwards during forward flight and are substantially vertically disposed when the helicopter is hovering [17].

Similar research has also been conducted on small scale propellers [19]. These propellers operate primarily in the low Reynolds number regime (under 100 000) where aerofoils experience a decrease in Lift to Drag ratio and as a result operate with far less aerodynamic efficiency (see Fig. 4.). It has been shown that ideal overlap separation for the Graupner 9 " $\mathrm{x} 5$ " E-prop is between $10 \%$ and $15 \%$ overlap and this is where the least amount of losses are experienced compared to propellers with no overlap.

A small number of investigations have been conducted into the simulation of overlapping forward flight rotors, one example of this was conducted by Lee et. al. [20]. This research varied the advance ratio and propeller axis and plane separation and determined that, at an advance ratio of 0.19 , normalized propeller axis separation of 0.7 (30\% propeller area overlap) and normalized propeller plane separation of 0.4 , there was no interaction between the individual propeller wakes. The 
distances were normalized using the propeller diameter. This means that the propellers are operating independently of each other in these conditions and thus there is no induced power loss. However, the overlap areas were only tested from $0 \%$ (no overlap) to $30 \%$ and thus make it difficult to compare.

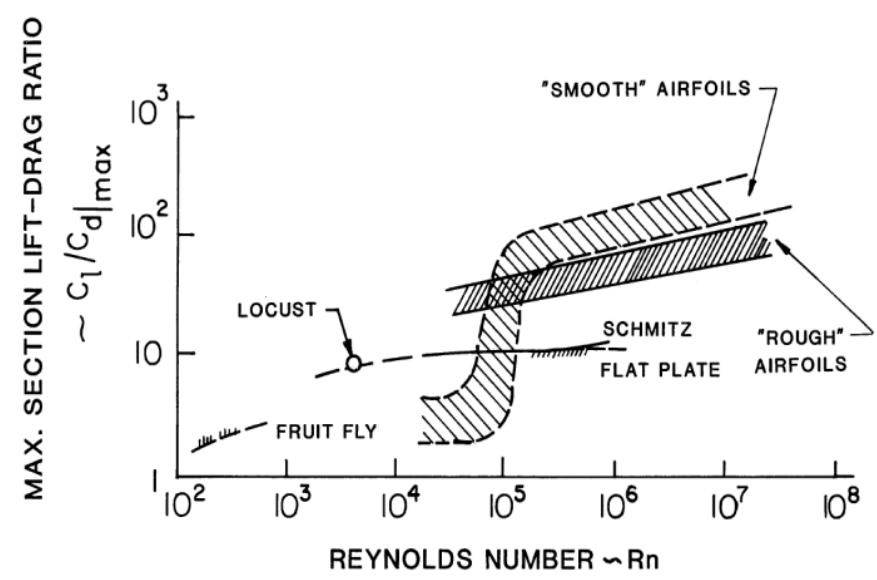

Fig. 4. Correlation between the Lift to Drag ratio and Reynolds number [18]

Both Brazinskas et. al. [21] and Ramasamy [22] investigated individual rotor performance for a co-axial and tandem setup, with Brazinskas focusing on the T-Motor 16" $\mathrm{x}$ 5.4" propeller and Ramasamy on hinged rotors. The experiments were conducted in a methodical manner and attempted to quantify the interference experienced by rotor overlap. The data gathered during these experiments is not suited to larger UAV mainly due to the difference in the Reynolds number for the T-Motor 16" x 5.4" and the lack of hinged rotor blades in large scale propellers.

Following the growth in size of rotary wing UAV's, propellers operating out of the low Reynolds number regime are becoming increasingly common, with this research tailored towards these UAVs during the hovering stage of the flight.

More specifically, the effect of the overlap area on power at a constant thrust and thrust at constant power for two T-Motor 28" $x$ 8.4" UL [23] propellers is examined, with the aim to quantify any benefits that arise as a result. 28" propellers are considered large in terms of scale propellers.

This paper is divided up into the following sections; Theory and Definitions provides an insight into the equations used and summarises the physical interactions; Experimental Setup defines the experiment conducted; Results analyses the data collected and presents this.

\section{Theory and Definitions}

Co-axial propellers offer a very high thrust density with only one boom being required to hold both propellers. Although this has structural benefits, this comes at the cost of propeller efficiency, with the downstream propeller operating in the wake (and thus interference with) the upstream propeller [24]. For greater efficiency, the propellers are required to operate without interference. This can be achieved by mounting the propellers on separate arms with clear separation between the propellers, ensuring that each propeller operates individually and to its designed efficiency.

Leishman and Syal (2008) have highlighting the four main cases for co-axial rotors. These are:

1. "The two rotors corotate in the same plane and are operated at the same thrust.

2. The two rotors corotate in the same plane but are operated at equal and opposite torque.

3. The rotors are operated at the same thrust but the lower rotor operates in the fully developed slipstream of the upper rotor.

4. The rotors are operated at balanced torque with the lower rotor operating in the fully developed wake of the upper rotor."

[25 p.23]

In addition to these configurations, the propellers can be positioned at various degrees of overlap and separation distances with associated losses in efficiency. The propeller percentage overlap area is calculated using the approximation found in Eq. (2).

$$
\text { Overlap Area }=A_{O}=1-\frac{d}{D}
$$

where $d$ is the normal separation of the propeller axes (stagger) (m) and $D$ is the propeller diameter (m) (Fig. 5.).

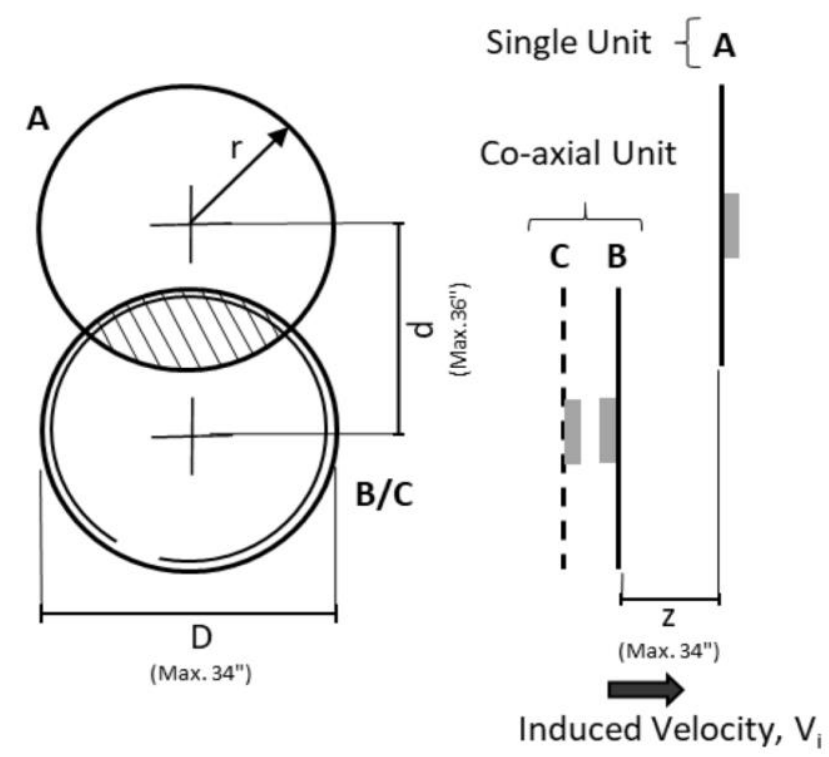

Fig. 5. Overlap of two propellers. Left: (frontal view) Propellers of equal diameter, $D$, with a propeller axis separation of $d$. The single unit (A) is represented above the co-axial unit (B/C). Right: (side view) A simplified view of the test setup showing the co-axial unit (B 
and C), single unit (A) and propeller plane separation, $z$. Dimensions are to the nearest inch

The tandem rotor helicopter represented in Fig. 6. has a rotor overlap of $34 \%$ which is similar to the $\mathrm{CH}-46$ Sea Knight and $\mathrm{CH}-47$ Chinook.

The Figure of Merit (FoM) of a propeller is a measure of the hover efficiency of a propeller, which is calculated from propellers working in static air and is given by Eq. (3).

$$
\text { Figure of Merit }=F O M=\frac{C_{T}^{\frac{3}{2}}}{\sqrt{2} C_{P}}
$$

where $C_{T}$ is the coefficient of thrust (Eq. (4)) and $C_{P}$ is the coefficient of mechanical power (Eq. (5)).

$$
C_{T}=\frac{T}{\rho n^{2} D^{4}}
$$

where $T$ is the thrust generated by the propeller $(\mathrm{N}), \rho$ is the density, $n$ is the revolutions per second and $D$ is the propeller diameter $(m)$.

$$
C_{P}=\frac{P_{i}}{\rho n^{3} D^{5}}
$$

where $P_{i}$ is the mechanical induced power supplied to the propeller (W). Eq. (3) shows that efficiency can be increased by increasing the thrust for a constant power or by decreasing the power for a constant thrust.
Applying the momentum theory to tandem rotors leads to Eq. (6):

$$
\frac{\left(P_{i}\right)_{\text {Total }}}{P_{i}} \approx\left[\sqrt{2}-\frac{\sqrt{2}}{2}\left(\frac{d}{D}\right)+\left(1-\frac{\sqrt{2}}{2}\right)\left(\frac{d}{D}\right)^{2}\right]
$$

Eq. (6) is a valid approximation to the theoretical result and assumes that the rotors provide the same amount of lift [26] When co-axial operation is observed, the induced power of the tandem propellers is equal to $\sqrt{2}$ of the induced power of two separate rotors and when the rotors are separated the induced power reduces to one. From this, the ideal efficiency can be calculated similarly to Eq. (3).

When propellers are placed in an overlapping configuration, the aerodynamic efficiency of the propellers decreases due to the interaction of the slipstream from the front propeller impacting the second propeller. However, less total area is taken up by the propellers which allows for a higher thrust density per unit propeller area and reduces the disk loading of the rotors [14].

During the overlapping operation of propellers, the forward rotor experiences either a small or positive change in performance [27]. As a result, this paper focuses on the performance of the aft rotor which is affected by the interference the most and is the main source of inefficiencies for a tandem rotor setup.

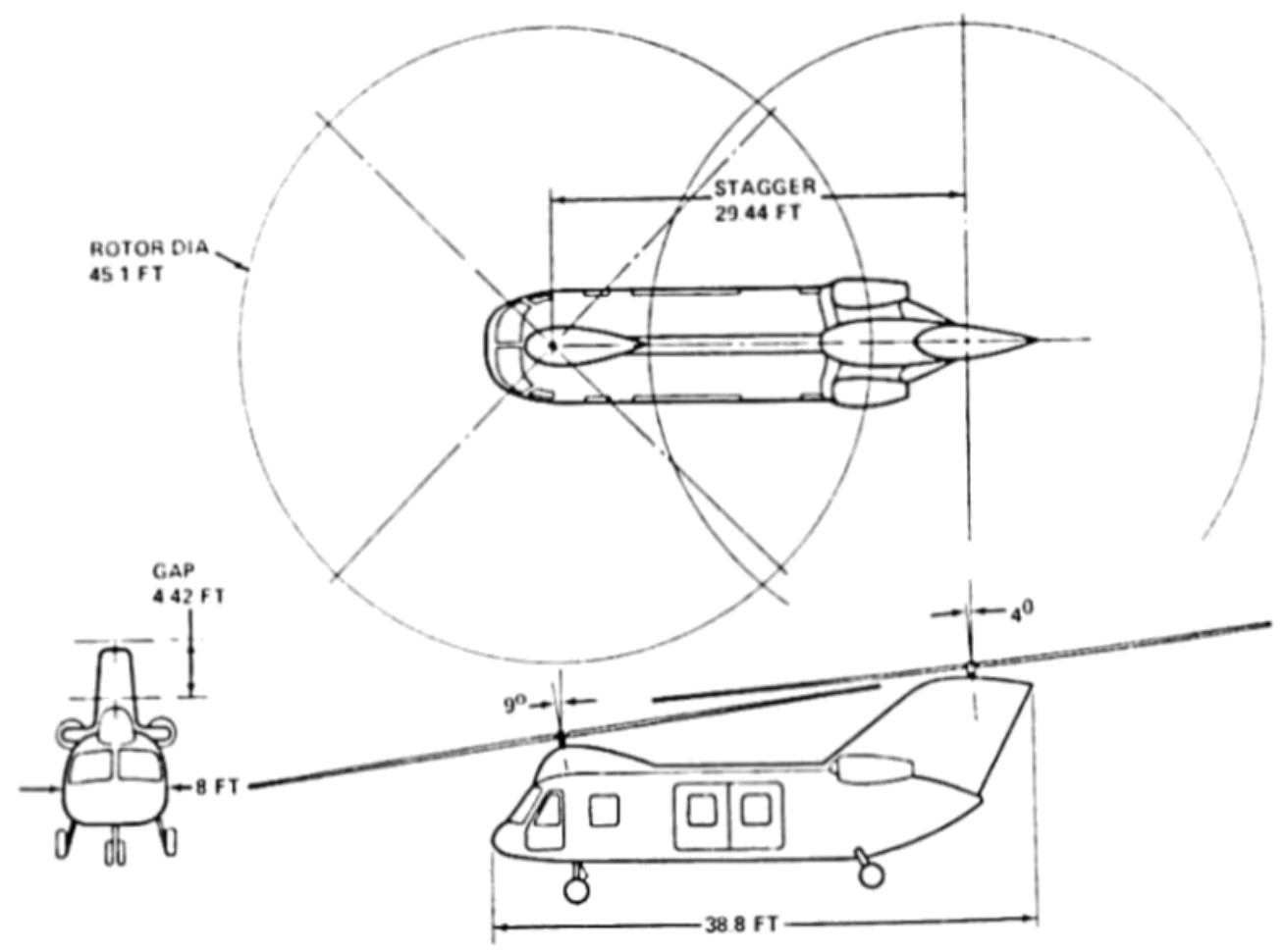

Fig. 6. - An illustration of propeller overlap, showing stagger, gap and rotor diameter [14] 


\section{Experimental Setup}

Tandem propeller configurations are evaluated with the use of a bespoke mount, using two RCBenchmark Series 1780 (S1780) [28] load cell units for data acquisition (Fig. 7). These contain three load cells per propeller and are able to determine the Thrust (N), Torque (Nm), Angular Velocity (RPM), Voltage (V) and Current (A) supplied to the setup (Table 1). The RCBenchmark software allows for simple operation of propellers through varying the ESC signal either manually or automated with the aid of a program to control the propellers. Real time data is plotted to aid with the performance visualization. The GUI is shown in Fig. 8.

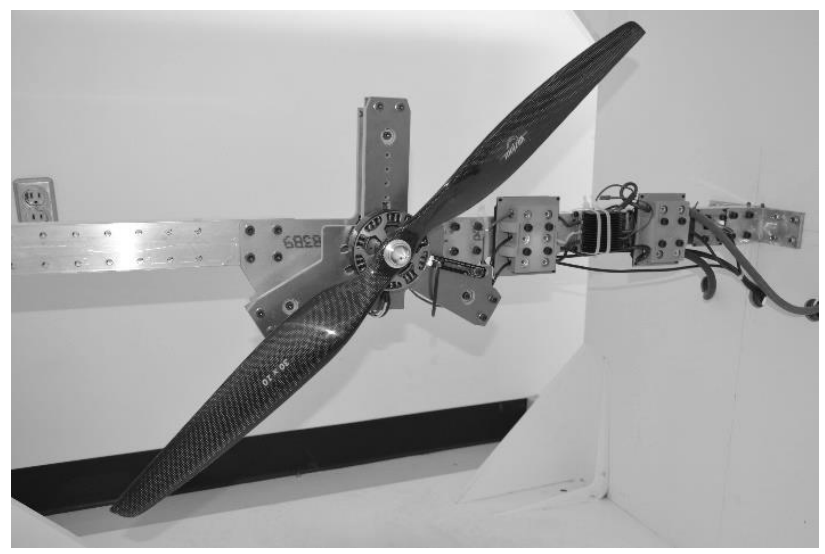

Fig. 7. Series 1780 RCBenchmark Single Motor Thrust Stand. Reproduced with permission [28] (S) RCoenchmariciom - Gul
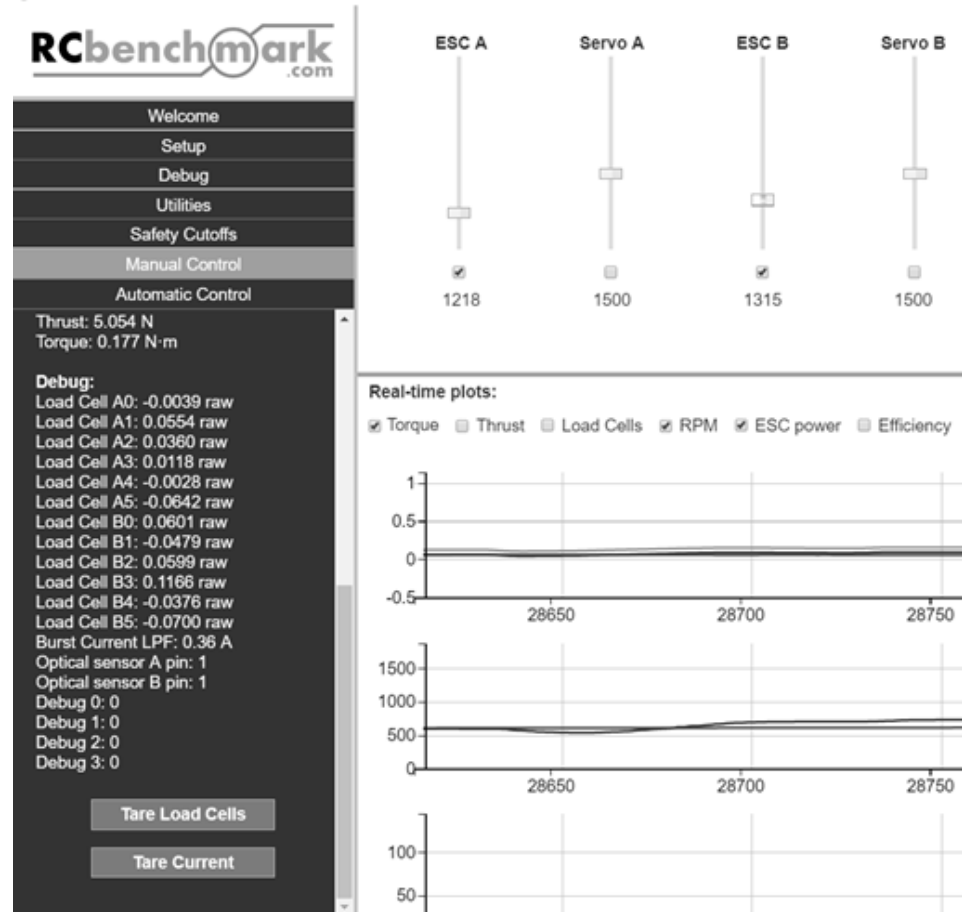

The S1780 Thrust stand comes with a kit to vary the propeller offset from the mount itself (ZDoF kit). This, however, is incapable of varying the overlap of two propellers and of evaluating the effect this has on performance. Hence, in order to collect efficiency data for different overlap areas using the S1780 Thrust stand, a special mount had to be designed and manufactured.

Table 1: Design specifications of the Series 1780 Single Motor version [28].

\begin{tabular}{|l|r|r|r|c|}
\hline Specification & Min. & Max. & Tolerance & Unit \\
\hline Thrust & -25 & 25 & $0.5 \%$ & $\mathrm{kgf}$ \\
\hline Torque & -12 & 12 & $0.5 \%$ & $\mathrm{Nm}$ \\
\hline Voltage & 0 & 60 & $0.5 \%$ & $\mathrm{~V}$ \\
\hline Current & 0 & 100 & $1 \%$ & $\mathrm{~A}$ \\
\hline $\begin{array}{l}\text { Angular Speed } \\
\text { (Optical RPM) }\end{array}$ & 0 & $190 \mathrm{k}$ & \pm 1 & $\mathrm{RPM}$ \\
\hline
\end{tabular}

The final design consists of a cage with a co-axial unit mounted between the walls and the single unit mounted on a cantilever beam on the roof (Fig. 9.). This beam can be moved vertically to vary the propeller overlap. It is capable of supporting up to 34 " propellers with a $150 \mathrm{~mm}$ gap to the nearest wall. For the base and sides of the mount, $18 \mathrm{~mm}$ thick OSB 3 boards were chosen. These are more economical than plywood of the same thickness and are easily able to contain a possible propeller failure as well as to resist the loads that the mount would experience from the propellers. Ideally, these boards would have been replaced with a series of wire meshes to break
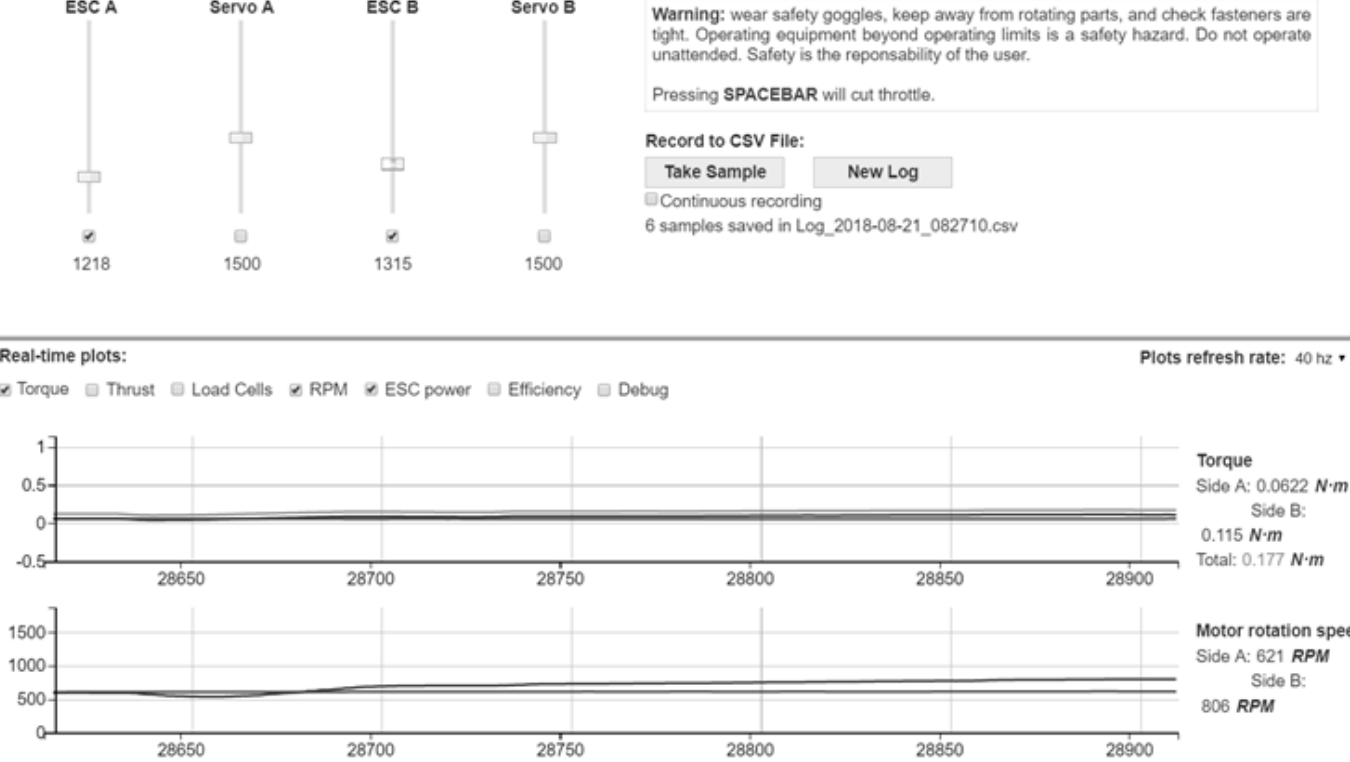

Motor rotation speed Side A: 621 RPM Side B: 806 RPM

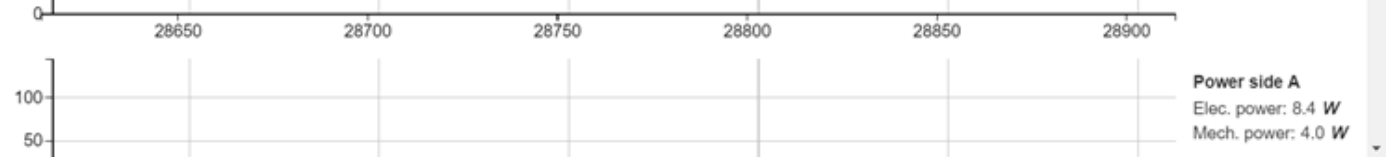

Fig. 8. GUI of the RCBenchmark software used to control the S1780 
up propeller fragments and catch any debris, as well as allowing air to move through the surface. The wooden boards are mounted onto a steel support frame of $50 \mathrm{~mm} \times 50 \mathrm{~mm} \times 5 \mathrm{~mm}$ steel angle sections. Two additional sections were subsequently added to the base of the mount in order to extend the life of the mount and to strengthen the base.

To ensure safety for the operators of this mount, mesh doors are installed on the intake and exit of the test section. These are wired up with micro-switches in order to cut the Electronic Speed Controller (ESC) signal and thus propeller rotation if the doors are opened.

The final design of this mount allows for the $\mathrm{z}$ offset (propeller axis of rotation) to vary by $305 \mathrm{~mm}$ without interference of a load cell unit, by $586 \mathrm{~mm}$ with a single load cell unit between the propellers and by $864 \mathrm{~mm}$ with two units between the propellers. The overlap of propellers can be varied from near co-axial operation to a $50 \mathrm{~mm}$ separation for a 34 " propeller leaving a $150 \mathrm{~mm}$ gap between the wall and the propeller as stated in the mount construction recommendation manual. The mount is able to vary the separation between the propeller planes (z) in $5 \mathrm{~mm}$ steps and the displacement of the propeller axes (d) with $10 \mathrm{~mm}$ accuracy. Table 2 summarizes the propeller mount capabilities.

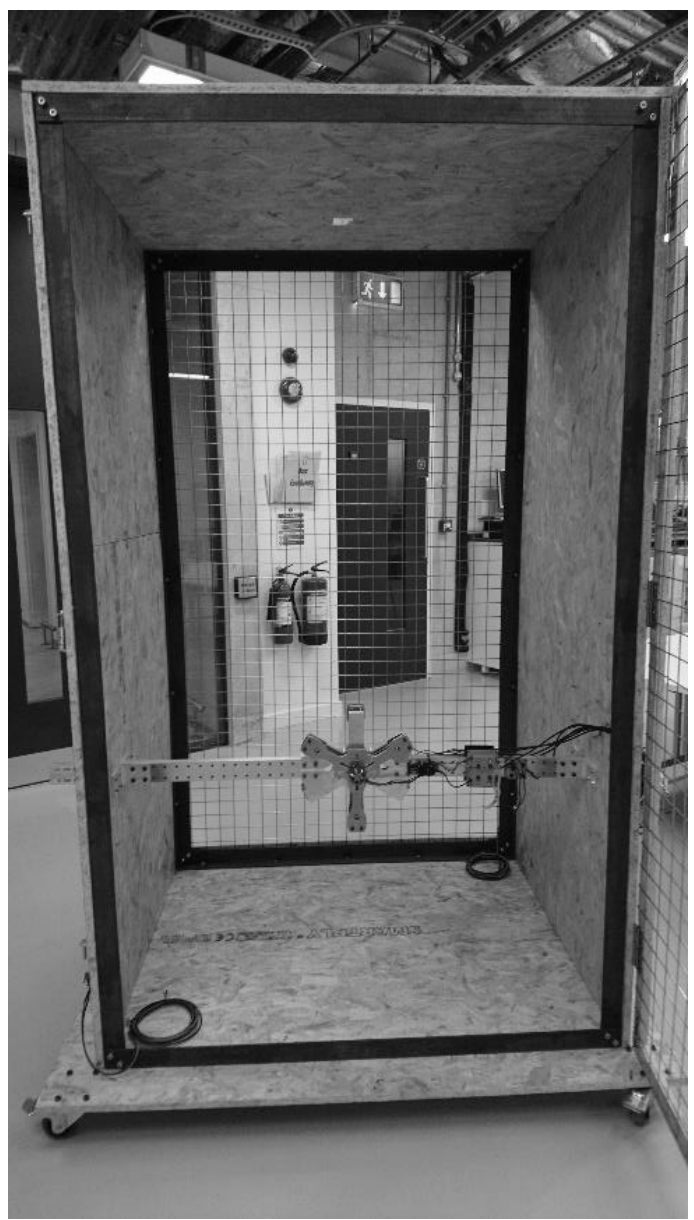

Fig. 9. - The S1780 co-axial unit in the bespoke mount
Table 2 - Propeller Overlap Mount - Physical Limitations

\begin{tabular}{|l|l|}
\hline Propeller Size & 34 ” \\
\hline Current & $60 \mathrm{~A}$ (Per Propeller) \\
\hline Thrust, single unit & $12 \mathrm{~kg}(117.7 \mathrm{~N})$ \\
\hline $\begin{array}{l}\text { Thrust, co-axial unit } \\
\text { (two mounting positions) }\end{array}$ & $25 \mathrm{~kg}$ Each (490.3 N Total) \\
\hline
\end{tabular}

The total mass of the mount is estimated at around 175 $\mathrm{kg}$, which is important as this helps to provide enough friction from the lockable wheels to stop the mount from moving under the thrust. The operational procedure is briefly outlined below.

The overlapping area can be calculated with the use of Eq. (2). The $z$ separation is normalized with the use of the propeller diameter $(D)$. Data was collected over the entire overlap range from $100 \%$ overlap (co-axial) to $0 \%$ overlap (no overlap) and compared to the case where the propellers operate in complete clearance (Fig. 10.). A representation of this is

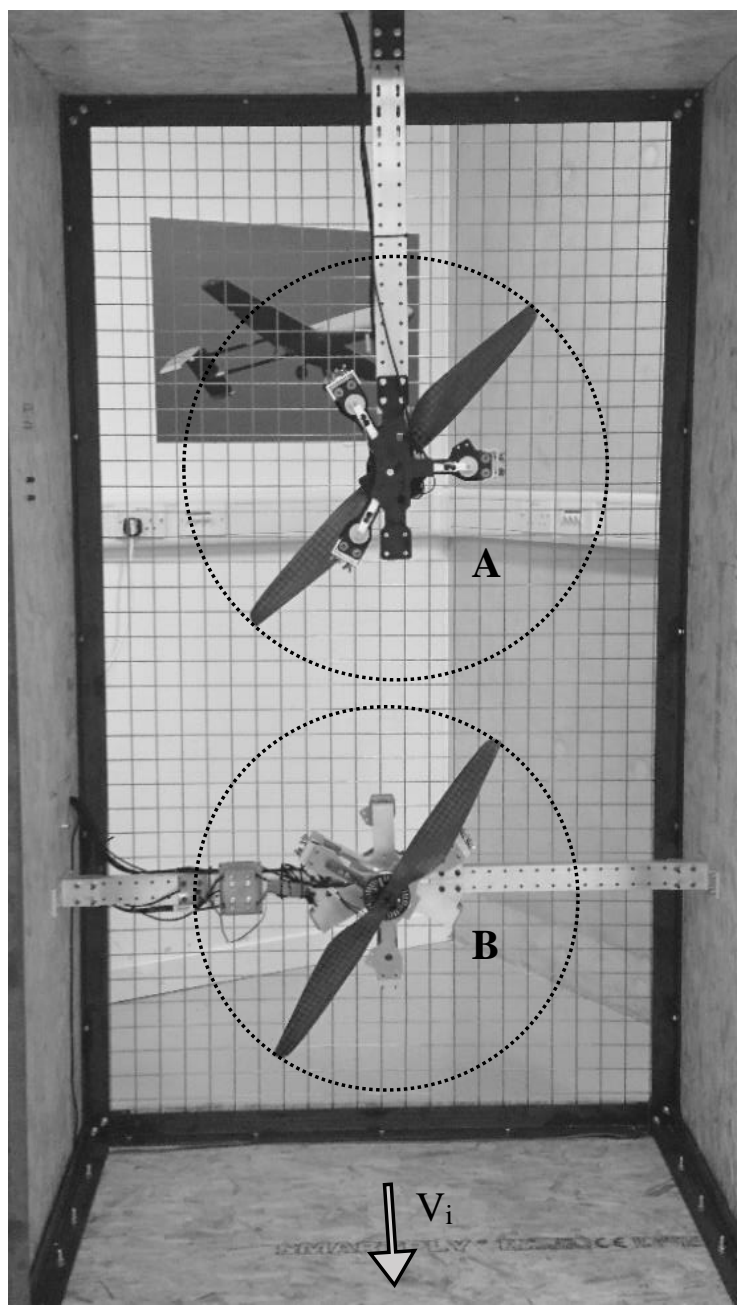

Fig. 10. - Complete clearance of two T-Motor 28" $\mathrm{x}$ 8.4" UL propellers. The arrow marks the induced velocity direction 
shown in Fig. 11. The case of 35\% overlap was additionally recorded for a comparison to Boeing's findings [13].

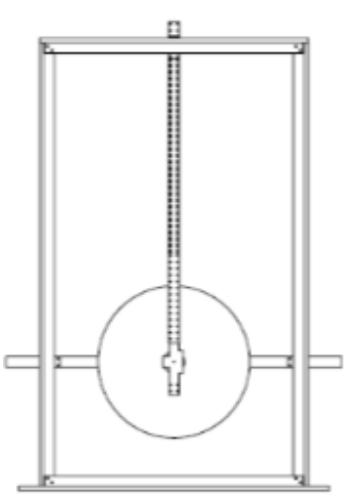

Co-axial

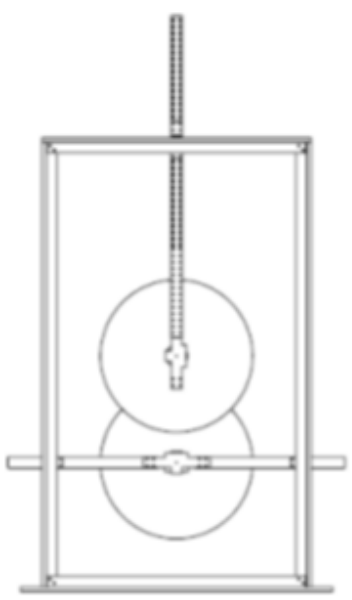

$30 \mathrm{~A}_{\mathrm{O}}$

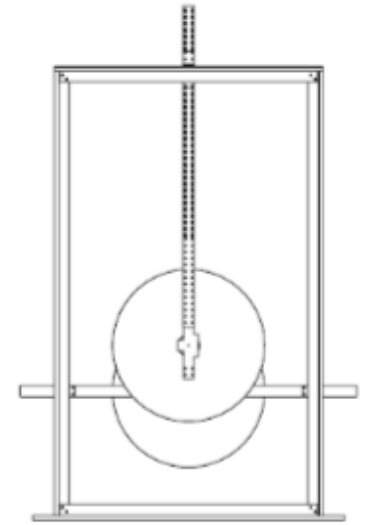

$70 \mathrm{~A}_{0}$

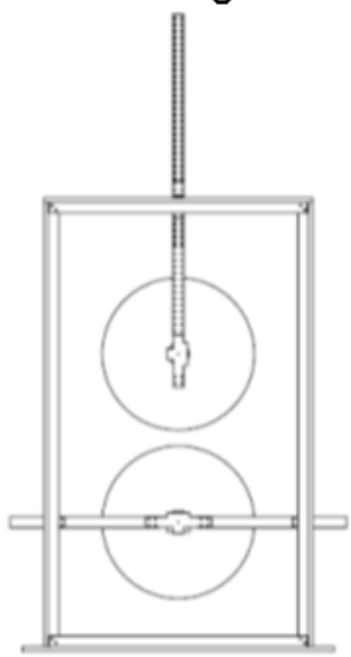

Clear
Fig. 11. Propeller setup with two 28 " propellers at various degrees of propeller area overlap (Ao)

Firstly, the $z / D$ (gap) distance between the propellers was adjusted using the ZDoF kits (Fig. 12.a) ). The distance had to be measured with a rule and was adjustable to the nearest slot present in the mounting brackets.

Secondly, the overlap area had to be adjusted by sliding the long supporting arm (fixed in a cantilever mount at the ceiling) vertically, a scale on the side of the cantilever beam was used for reference. It was fixed by four brackets to the ceiling for a secure support. Fig. 10. and 12.b). illustrate its implementation. The wires were shifted up with the beam and secures on the outside of the test-rig to minimise the possibility of damage to the equipment and to the propellers during testing.

Subsequently, the test-rig was secured for the testing to commence. Ensuring that the test-rig was empty, upon which both doors were locked, engaging the door safety switches. The battery was connected and the main cut-off switch disengaged.

Using the RCBenchmark software, the propellers could now be manually controlled. For the area overlap tests, the propellers were spun up simultaneously in steps of a fixed RPM.

For the test, 28" $\mathrm{x} 8.4$ " UL propellers were used in conjunction with $100 \mathrm{Kv}$ U8 motors by T-Motor [23]. These were connected to a $4500 \mathrm{mAh} 6 \mathrm{~S} \mathrm{Li}-\mathrm{Po}$ battery with $40 \mathrm{~A}$ Maytech speed controllers. For the U8 motors with the 28 " $\mathrm{x}$

a)

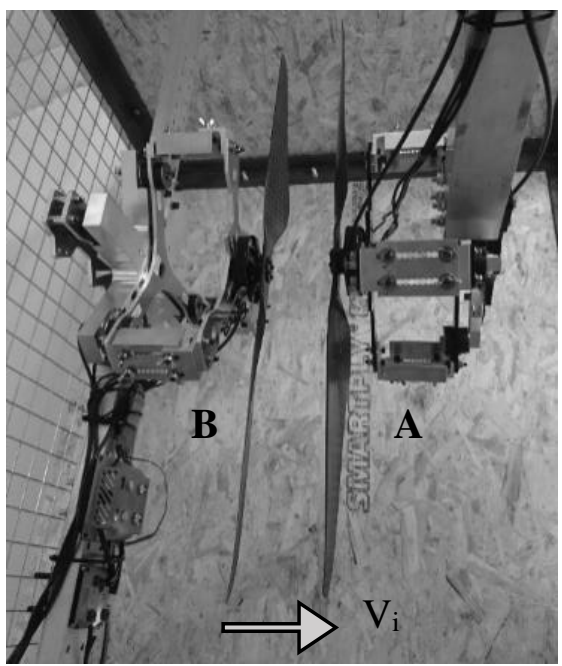

b)

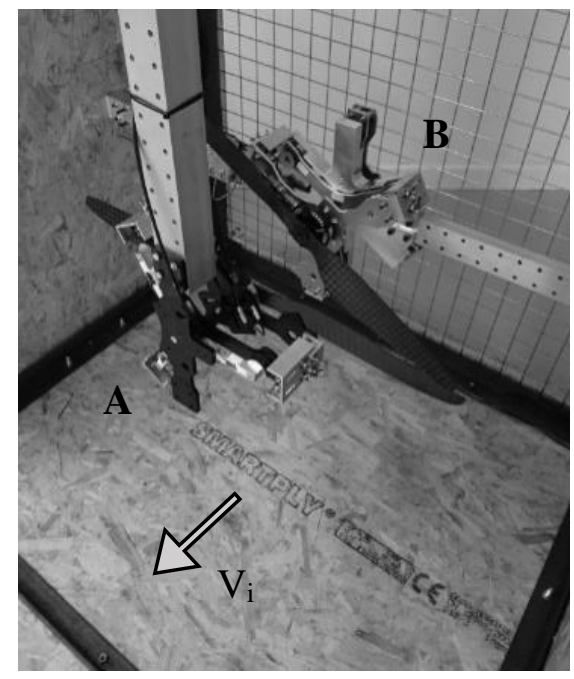

Fig. 12. - a) clearly shows how the $\mathrm{z} / \mathrm{d}$ distance can be varied with the ZDoF kits for two T-Motor 28" x 8.4"UL propellers in near co-axial testing. b) near co-axial operation of two T-Motor 28 " x 8.4"UL propellers (additional view). The induced velocity direction is marked by the arrow respectively

8.4" UL propellers, the speed was limited to 1800 RPM. This limit was set because a speed of 2000 could not be reached reliably for both propellers each time. 
Fig. 13. is a plan view image of the T-Motor 28 " $\mathrm{x}$ 8.4"UL propeller used for the experiments with Fig. 14. representing the chord and pitch (measured to the nearest degree). The physical properties of the T-Motor 28" x 8.4"UL propeller are summarised in Table 3.

Table 3 - Physical Properties of the T-Motor 28" x 8.4"UL Propeller. T-Motor 28" x 8.4"UL Propeller

\begin{tabular}{|l|c|}
\hline Propeller Diameter & 28 ” \\
\hline Pitch & $8.4 ”$ \\
\hline Propeller Mass & $55 \mathrm{~g}$ \\
\hline Solidity (Without non-lifting section) & 0.0784 \\
\hline Optimum Angular Velocity (RPM) & 2000 \\
\hline Thrust Limitation & $10 \mathrm{~kg}$ \\
\hline Thrust Constant & 5.0117 \\
\hline Thrust Factor & 2.0544 \\
\hline Power Constant & 19.256 \\
\hline Power Factor & 2.9946 \\
\hline Tip Mach Number at 1800 RPM & 0.195 \\
\hline Materials & Carbon Fibre and Epoxy \\
\hline
\end{tabular}

This propeller has been chosen for the experiments as it operates primarily outside of the low Reynolds Number regime as can be seen by Fig. 15. Table 4 summarises the data of the remaining components of the power-train used.
Table 4-Physical Properties of the Motor, ESC and Battery used. T-Motor U8 $100 \mathrm{Kv}$ BLDC Motor

\begin{tabular}{|l|c|}
\hline Measured Voltage Constant & $105 \mathrm{Kv}$ \\
\hline Max. Unloaded Angular Velocity (approx.) & $2370 \mathrm{RPM}$ \\
\hline Max. Continuous Current (for 180 s) & $8 \mathrm{~A}$ \\
\hline Max. Continuous Power (for 180 s) & $179 \mathrm{~W}$ \\
\hline No. of Cells (Li-Po) & $6-12 \mathrm{~S}$ \\
\hline Configuration & $36 \mathrm{~N} 42 \mathrm{P}$ \\
\hline Mass (excluding cables) & $240 \mathrm{~g}$ \\
\hline Dimensions & (Dia.) 86.8 x 26.5 mm \\
\hline \multicolumn{2}{|c|}{ MayTech 40 A - OPTO ESC with no BEC }
\end{tabular}

\begin{tabular}{|l|c|}
\hline Max. Current & $40 \mathrm{~A}$ \\
\hline Rating & $2-6 \mathrm{Li}-\mathrm{Po}$ \\
\hline Mass & $45 \mathrm{~g}$ \\
\hline Time Setting & Automatic \\
\hline PCB Dimensions & $70 \times 30 \times 11 \mathrm{~mm}$ \\
\hline
\end{tabular}
Turnigy 4500 mAh 6 S Li-Po Battery

\begin{tabular}{|l|c|}
\hline Minimum Capacity & $4500 \mathrm{mAh}$ \\
\hline Constant Discharge Rate & $30 \mathrm{C}$ \\
\hline Peak Discharge Rate & $40 \mathrm{C}$ \\
\hline Mass & $745 \mathrm{~g}$ \\
\hline
\end{tabular}

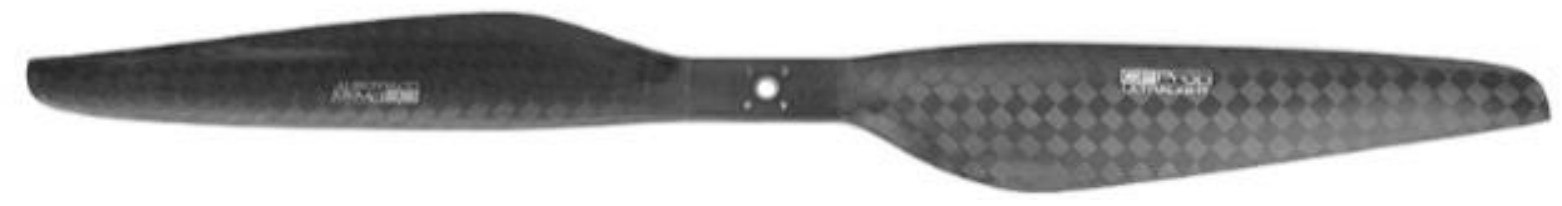

Fig. 13. Top view of the T-Motor 28” x 8.4" UL propeller [23]

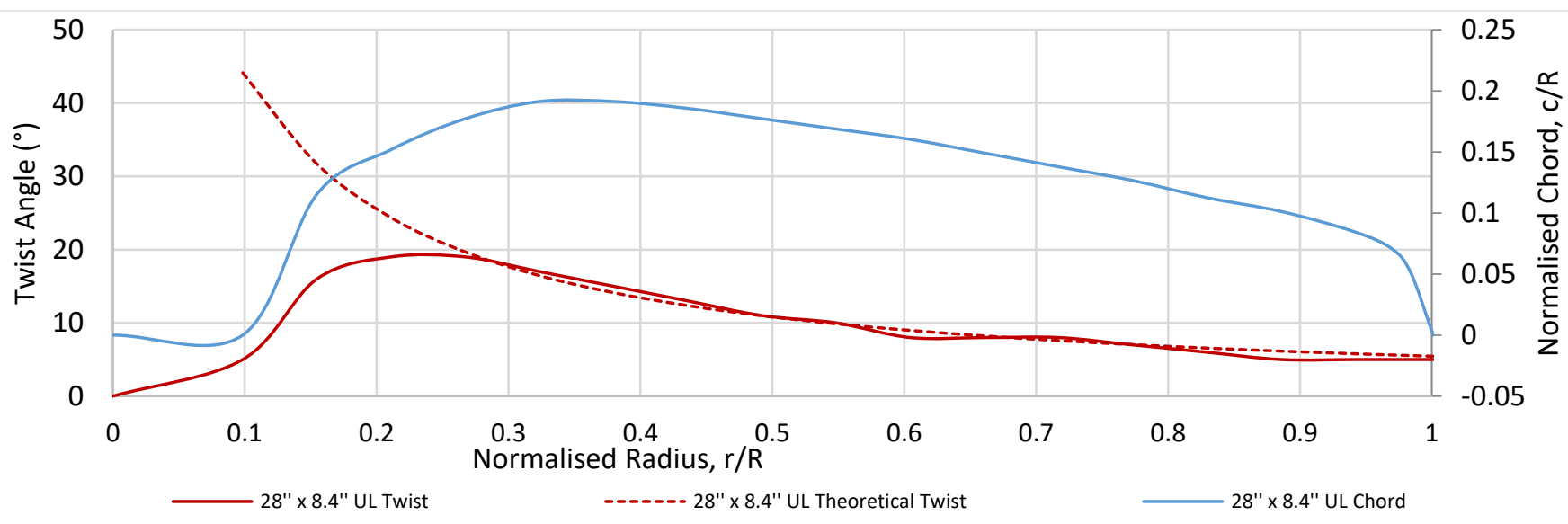

Fig. 14. Geometric representation of the 28 " x 8.4" UL 


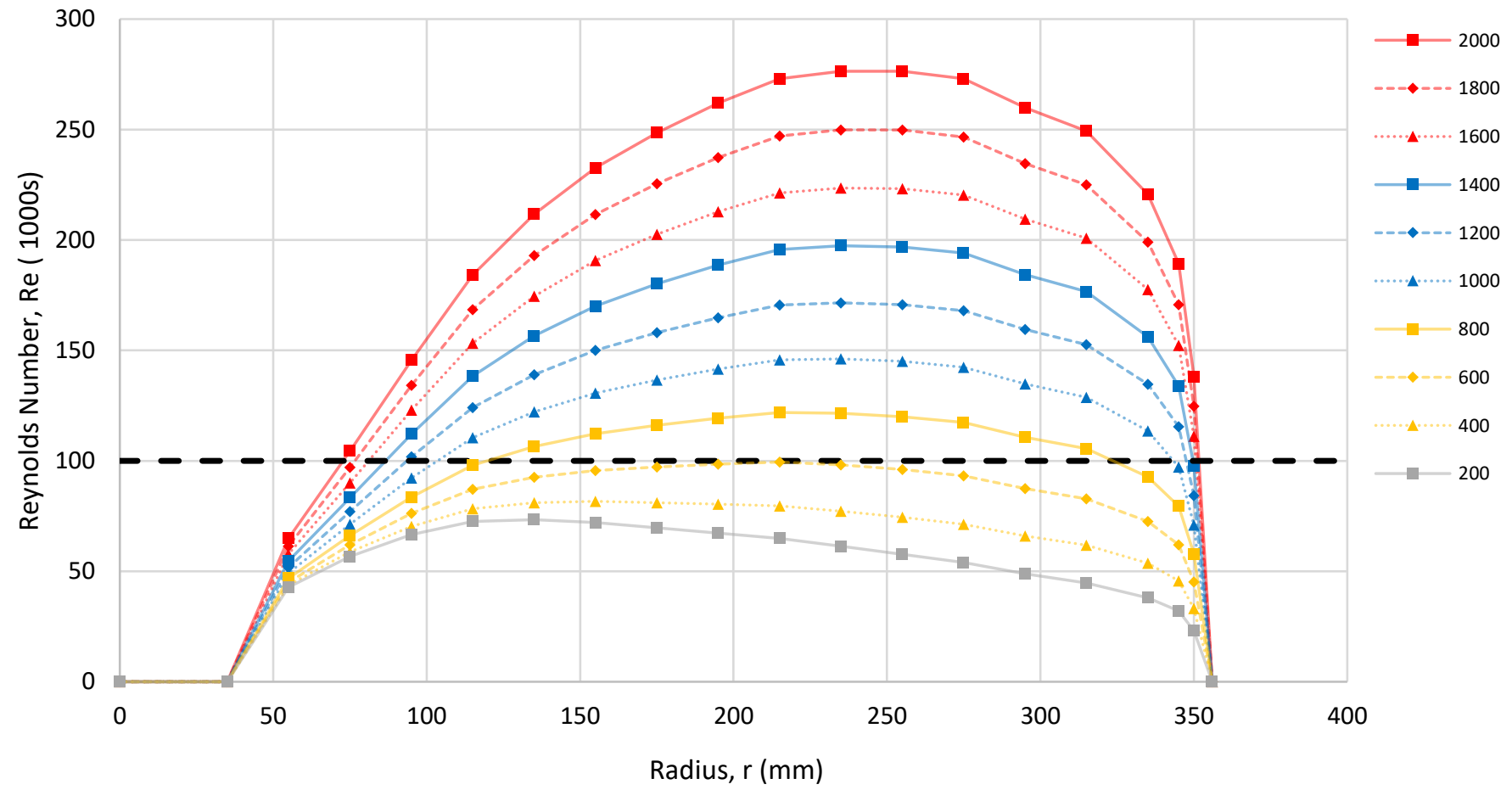

Fig. 15. The calculated Reynolds Numbers experienced along the T-Motor 28" x 8.4" UL propeller at different rotational speeds

\section{Results}

The data presented below was collected with both propellers in torque balance (Case 4 [25]) with the forward propeller varied at constant rpm values ranging from $400 \mathrm{rpm}$ up to $1800 \mathrm{rpm}$ and the aft propeller was spun as fast as necessary to match the torque produced by the forward propeller. $1800 \mathrm{rpm}$ represents the maximum reliable rotational speed that can be achieved with the $6 \mathrm{~s}$ Li-Po battery, three samples were averaged for each data point. In addition to investigating the effect of propeller overlap on rotor performance, the effect of the geometric interference of the S1780 single and co-axial units was investigated using a single T-Motor 28" x 8.4"UL propeller.

The performance of a single T-Motor 28" $\mathrm{x}$ 8.4"UL propeller is summarised in Fig. 16-20. showing the thrust, torque and input power of the propeller at various speeds and throttle settings with equations for the best fit curves. This data is compared to the data provided by T-Motors [23] in Fig. 16. which shows a good correleation with the T-Motors preformance data using the same propeller and motor. Fig. 18. shows the variation in recorded thrust through running the propeller with different thrust stand interference locations. These include upstream and downstream interference of both the single S1780 thrust stand (A) and the co-axial S1780 thrust stand $(\mathbf{B} / \mathbf{C})$, with an average percentage difference of $5.5 \%$ in thrust between the upstream and downstream interferences of the single and co-axial units. Using the Actuator Disk Theory and assuming that the thrust stand has a coefficient of drag of
1.05 due to the square cross-sections and sharp corners present a measured thrust increase of $5.3 \%$ was calculated which corresponds well with the experimental values. This implies that the drag from the test rig increases the measured tension of the load cells and thus increases the thrust measurement.

The efficiency of the T-Motor U8 $100 \mathrm{Kv}$ motor used in the experiments as a function of rotational speed is represented in Fig. 21. and shows clearly that the efficiency of this motor increases with rotational speed. It also shows that this motor reaches a peak efficiency of around $82 \%$ at 2000 RPM and is ideally matched to the T-Motor 28" x 8.4"UL propeller whose design point is also at 2000 RPM. The peak motor efficiency of $82 \%$ agrees well with data provided by T-Motors [23] as well as with findings by Miyamasu and Akatsu [10]. The voltage constant was measured for both motors used in this experiment with an AEO Technology K3 Kv/RPM Meter and were both found to have a $\mathrm{Kv}$ rating of 105 . This is a $5 \%$ difference to the stated $\mathrm{Kv}$ value. 


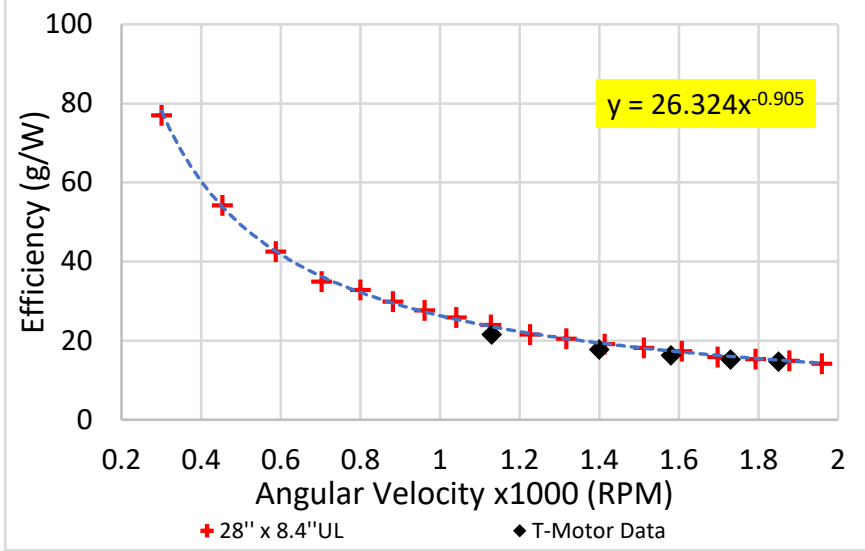

Fig. 16. Efficiency of the T-Motor 28" x 8.4"UL compared to data given by T-Motors [23]

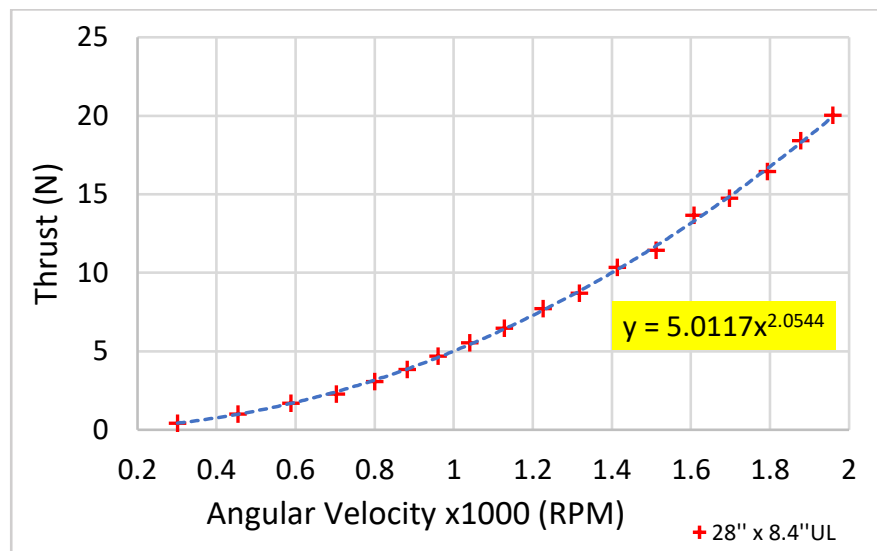

Fig. 17. Thrust of the T-Motor 28 " $\mathrm{x} 8.4$ "UL propeller mounted on the Single S1780 Unit (A)

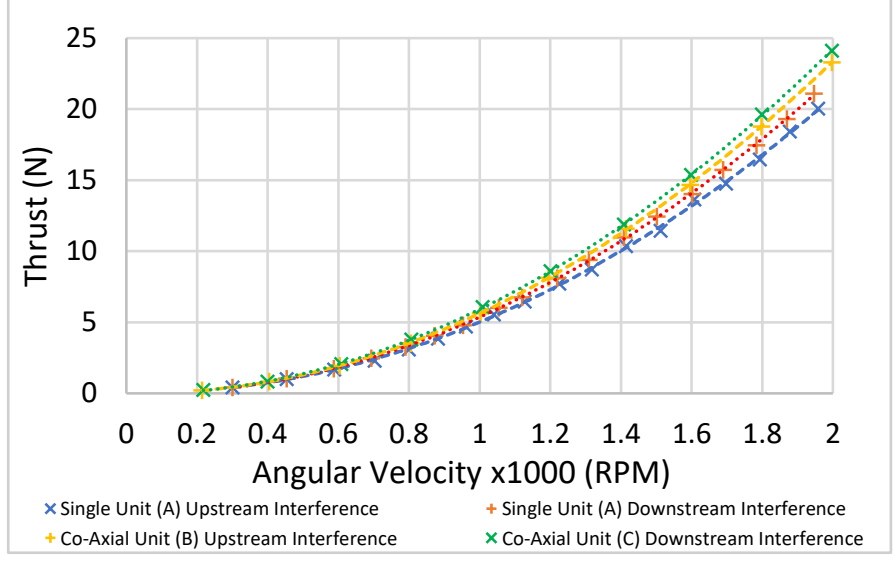

Fig. 18. Thrust of the T-Motor 28" x 8.4"UL propeller at different mounting locations on the 1780 single and co-axial thrust stands

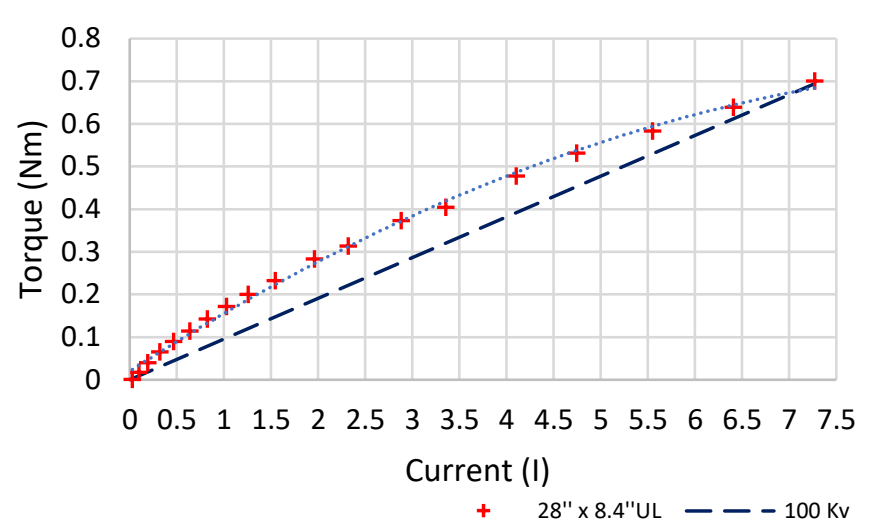

Fig. 19. Torque of the T-Motor 28" x 8.4"UL propeller as a function of induced current mounted on the Single S1780 Unit (A). A theoretical gradient of $100 \mathrm{Kv}$ is also shown

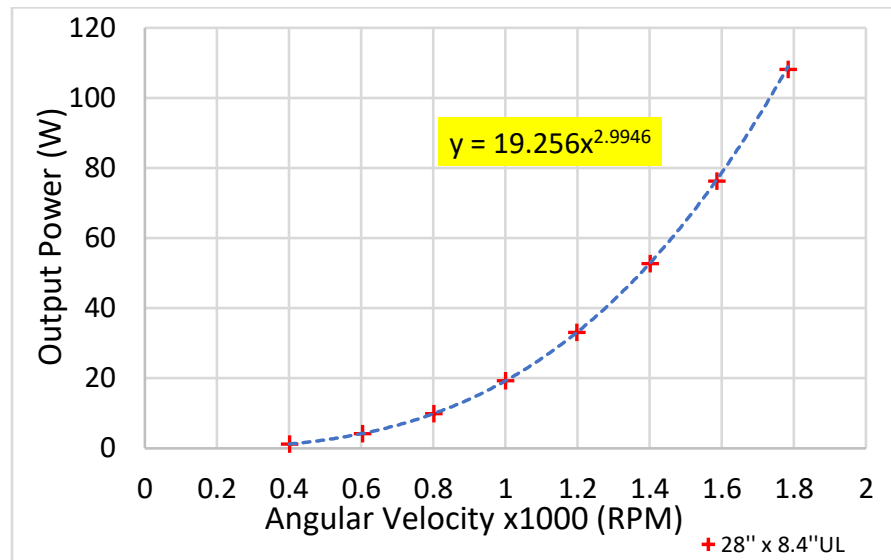

Fig. 20. Output Power of the T-Motor 28" x 8.4"UL propeller as a function of rotational speed mounted on the Single S1780 Unit (A)

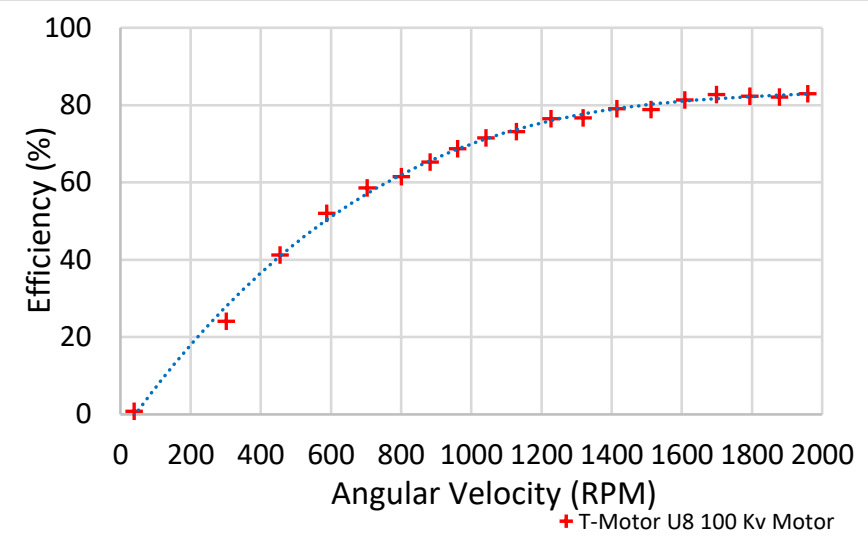

Fig. 21. Efficiency performance of the T-Motor U8 $100 \mathrm{Kv}$ motor plotted against angular velocity 
Fig. 22. shows the variation of Figure of Merit with the coefficient of thrust for the T-Motor 28" x 8.4" UL propeller. Here it can be seen that the aft (upper) propeller is not affected by the overlap of the propellers, with the fwd (lower) propeller seeing both a reduction in coefficient of thrust and Figure of Merit (FM). The FM decreases from a peak value of 0.66 to 0.42 with a profile drag increase (Cdo) from 0.02 to 0.035 , as well as an induced power factor $(\mathrm{k})$ increase from 1.15 to 1.28.

As can be seen from Fig. 23., the power ratio stays almost constant over the range of $d / D$ values. However, as the rotors overlap from fully isolated $(d / D=1)$ to fully co-axial $(d / D=0)$ the Thrust ratio $\left(\mathrm{T}_{\mathrm{L}} / \mathrm{T}_{\mathrm{U}}\right)$ changes from approximately 1.0 to 0.75 . This transition occurs at almost exactly $d / D=0.5(50 \%$ overlap) and shows the effect that the upper rotor has on the lower rotor at small $z / D$ ratios. This figure verifies that at the chosen overlap of $-18 \%$ the propellers are operating in isolation, each providing the same thrust (average thrust ratio $=$ 1.007) and torque.

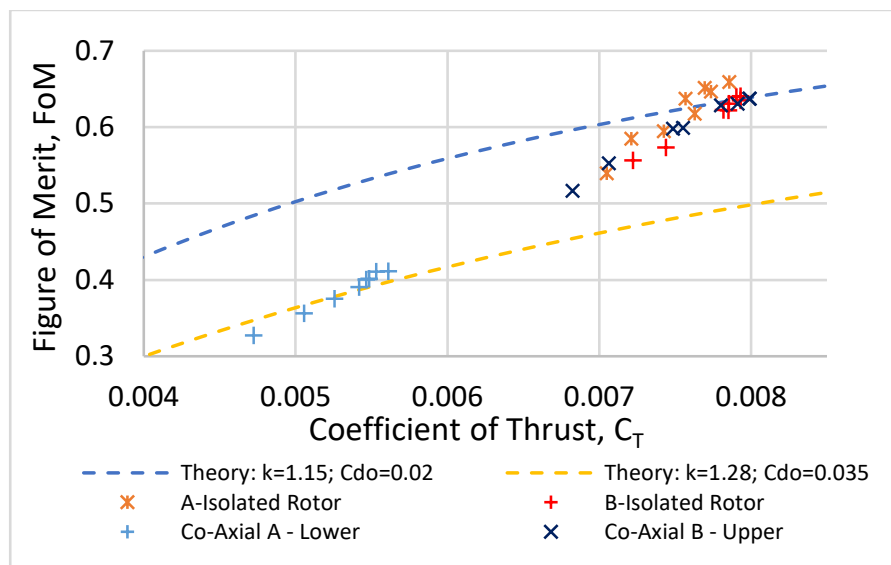

Fig. 22. Performance of two T-Motor 28" x 8.4"UL propellers both isolated and co-axial compared to theoretical results

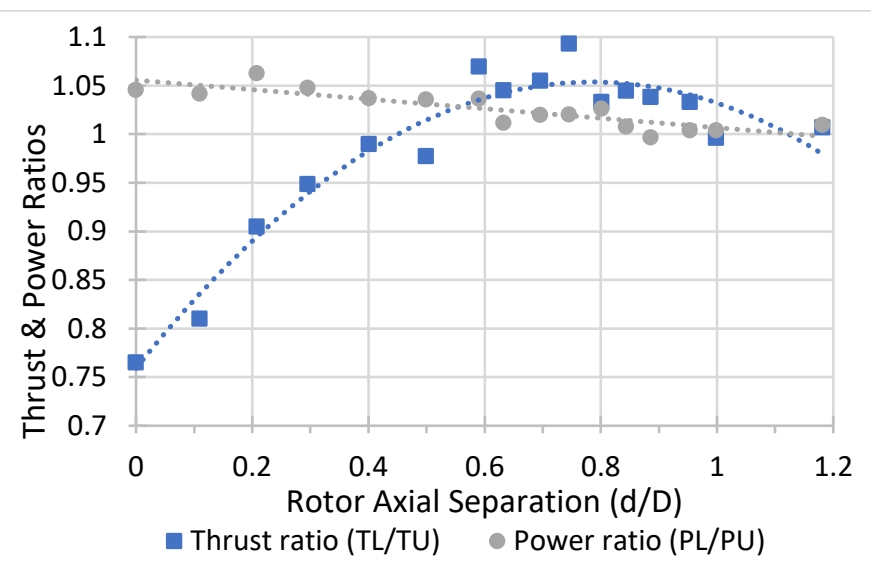

Fig. 23. Thrust and power ratios plotted against rotor axis separation for a normalised $\mathrm{z}$ distance of 0.1 for torque balanced propellers
The data collected at various overlap areas was finally plotted to represent the percentage difference in power for a constant thrust and percentage difference in thrust for a constant power. The results represent the performance of both forward and aft propeller.

Fig. 24. a) and b) show a clear region of beneficial influence between the two 28 " $\mathrm{x} 8.4$ " UL propellers between $10 \%$ and $20 \%$, with both increases in power at a constant thrust and increases in thrust at a constant power. A complete co-axial configuration, however, results in a $13 \%$ loss of thrust at a constant power. This is very disadvantageous for UAV designs and the hovering endurance of these systems.

Fig. 24. also replicates the findings by the Boeing VERTOL company recommended to the USAAVLABS [13] which later led to the design of the $\mathrm{CH}-46$ Sea Knight and the $\mathrm{CH}-47$ Chinook - at $34 \%$ overlap there are small losses in power for a constant thrust compared to two propellers operating in isolation which allows for the most compact platform without incurring severe efficiency losses from the interference of the two propellers. From Fig. 24. it is clear to see as to why $35 \%$ overlap is the cut-off point for tandem rotors, with propeller performance rapidly degrading with increased overlap area after this point to a minimum around $90 \%$ to $100 \%$ area overlap.

Tests conducted on a co-planar setup by NASA [29] determined that at an approximate 38\% area overlap a $14 \%$ power loss can be experienced compared to two co-planar rotors operating with clear separation. The rotors in this setup were 15 $\mathrm{ft}$ to $15.25 \mathrm{ft}$ in diameter and, opposed to the set-up in this journal, were able to flap. Fig. 24. shows that for the T-Motor 28 " $\mathrm{x} 8.4$ "UL propellers at an overlap area of $38 \%$ a power difference at a constant thrust to the clear separation case of about $4 \%$ can be expected. The rotor setup tested by NASA meant that both rotors were equally affected by the overlap due to acting in a co-planar set-up whereas when the propellers operate with separation between the propeller planes, the aft propeller experiences greater losses than the forward propeller due to the interaction of the aft propeller with the downwash of the forward propeller [20] [21]. This makes up the majority of the losses experienced by such a system and results in a reduced loss compared with a co-planar set-up.

Fig. 25. represents two T-Motor 28" x 8.4"UL propellers in the same set up as used to collect the other overlap data with the propellers operating at equal angular velocities rather than in torque balance. This case results in a net torque for the propeller setup and thus represents a propeller pair on a multi-copter where multiple sets such as this operate together to achieve overall torque neutrality.

The same trends can be observed as in Fig. 24. with a slightly more exagerated trend: there are greater benefits for a larger overlap region (up to almost $30 \%$ compared to around 
a)

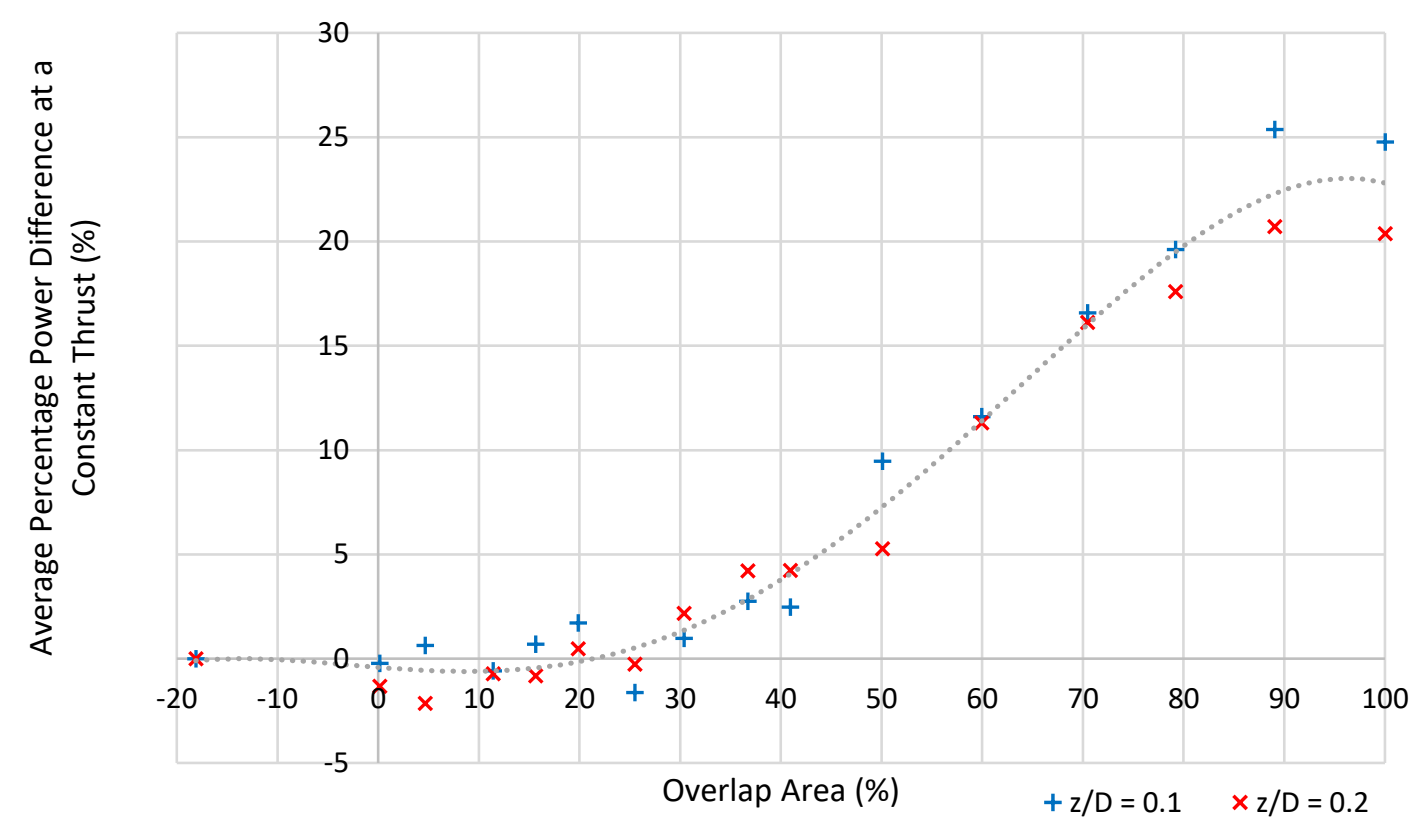

b)

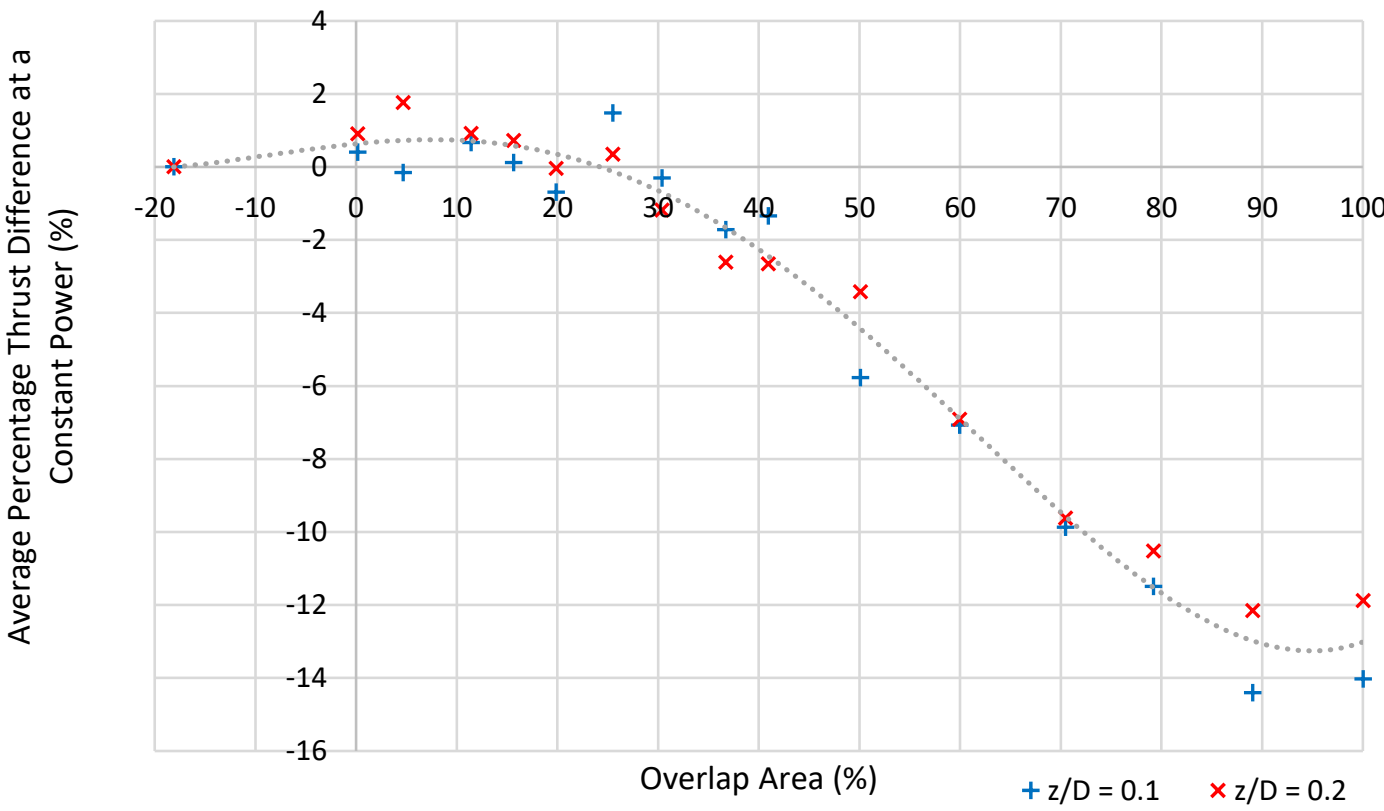

Fig. 24. Summary of results of (a) percentage power difference at constant thrust. (b) percentage thrust difference at constant power for torque balanced propellers

$20 \%$ ) as well as greater losses for a co-axial setup. Both Fig. 24. and Fig. 25. exhibit a small drop in losses between $90 \%$ overlap and co-axial. This greater interference is due to the fundamentals of propeller design. When the propellers are in a pure co-axial configuration, the area of induced velocity of the upstream propeller is directly impacting the centre of the downstream propeller. This is where the propeller is mounted to the motor where there are usually no aerofoil sections. Due to 
a)

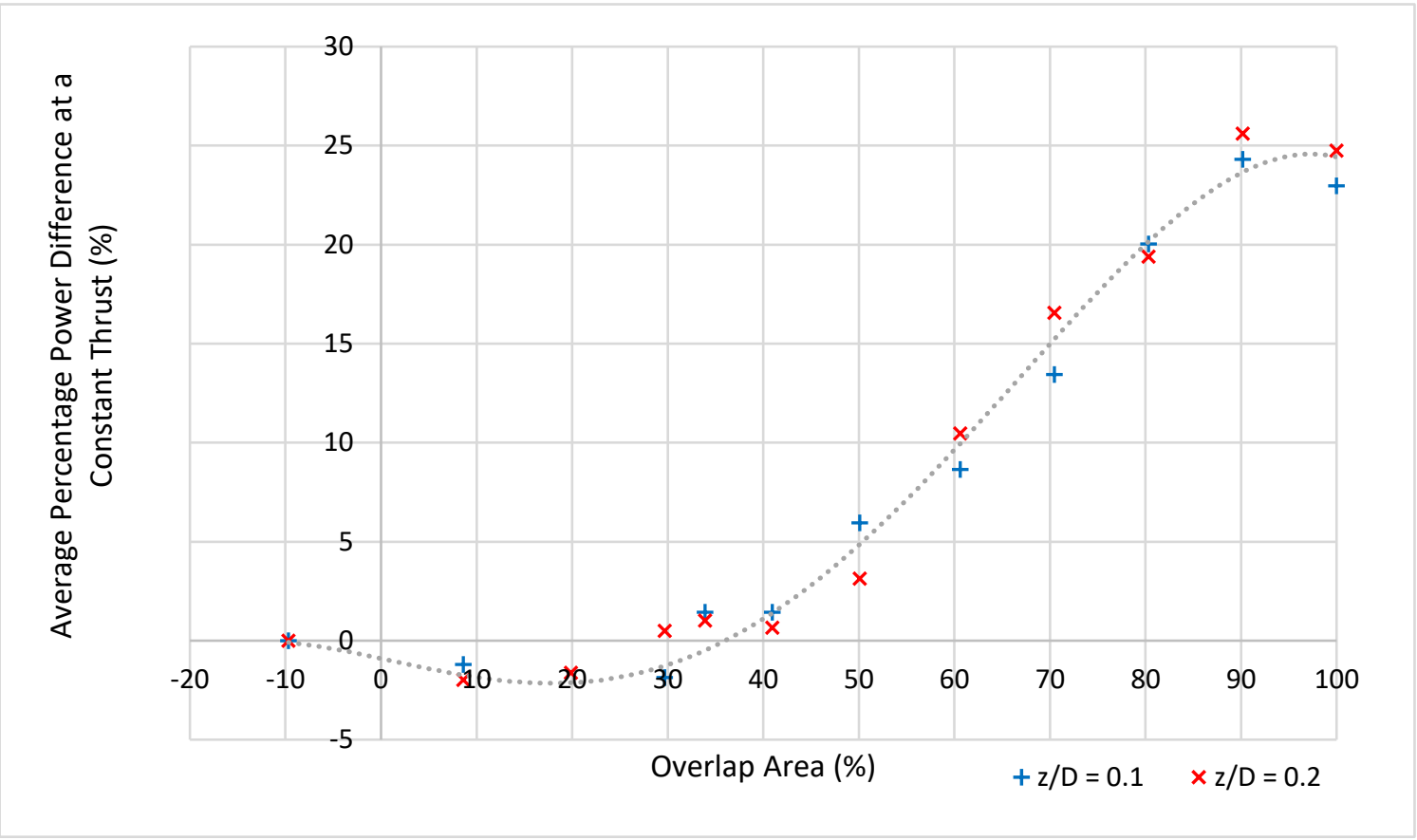

b)

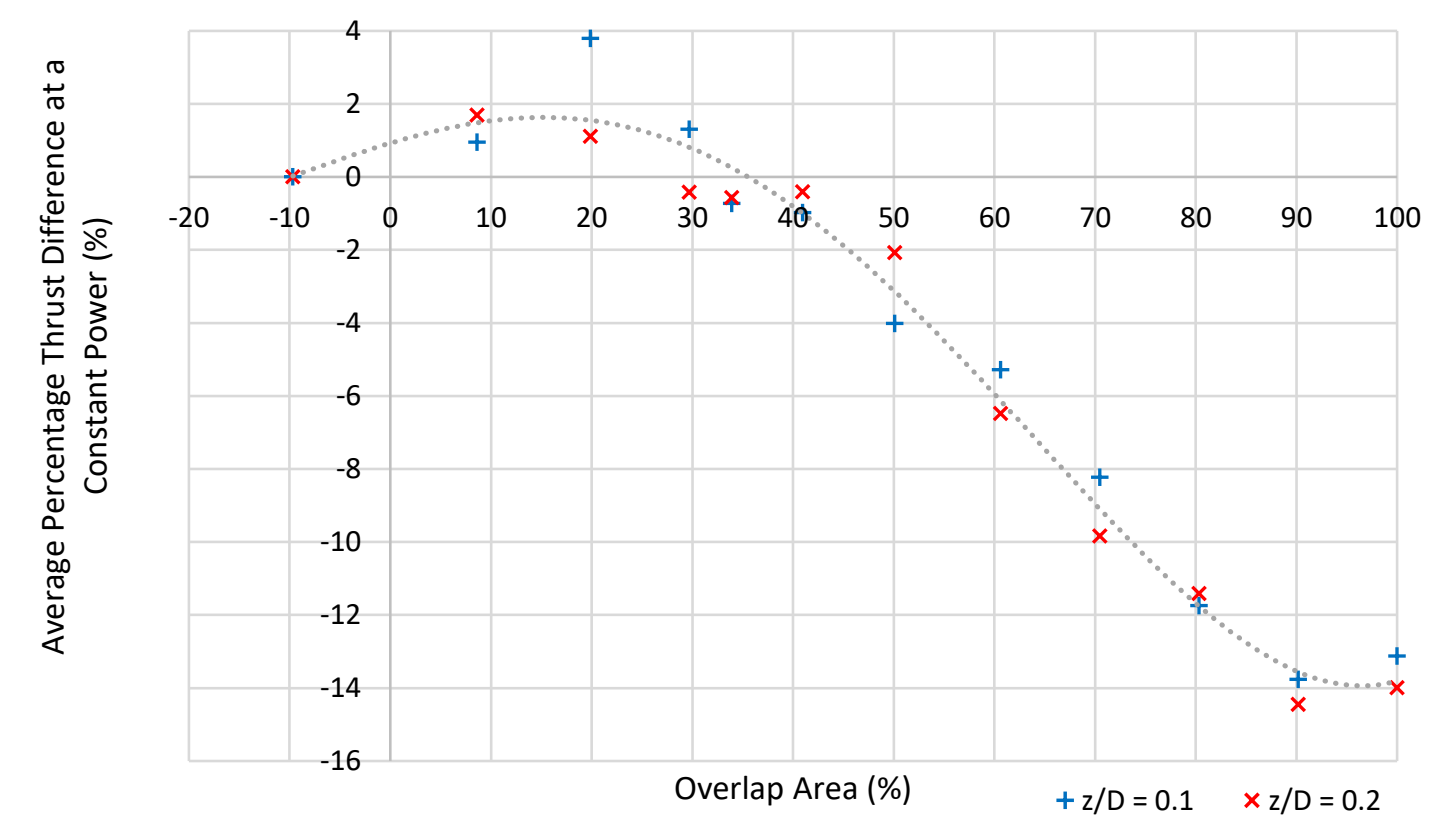

Fig. 25. Summary of results of (a) percentage power difference at constant thrust. (b) percentage thrust difference at constant power for angular velocity balanced propellers

the low rotational velocity in this area, is no aerodynamic advantage to be gained from having aerofoil sections here. As a result of this, the interference area from the upstream propeller on the downstream propeller covers less aerodynamically contributing areas of the downstream propeller when compared to the $90 \%$ area overlap case and thus the co-axial case has reduced total interference loss. 


\section{Conclusion}

The T-Motor 28" x 8.4"UL propeller has been analysed in depth using the RCBenchmark S1780 Thrust stand with some of the investigation looking at the stand itself. This investigation into the S1780 single and co-axial units has resulted in the determination of the effect that the interference of these units has on the propeller performance. A maximum variation of $15.2 \%$ in the thrust measured was observed when measuring the propeller performance between the mounting locations. The propeller efficiency data generally agreed well with the data provided by $\mathrm{T}$-Motor when using the thrust stand offering the least interference. The performance of an individual T-Motor 28 " $x$ 8.4"UL propeller was well documented and the T-Motor U8 $100 \mathrm{Kv}$ motors used in the study were found to be performing identically at a measured $105 \mathrm{Kv}$.

With the rise of UAVs specifically designed for hovering, the benefit shown in this research can make a significant contribution to increasing the endurance of drones. The data collected through the series of experiments has quantified the inefficiencies generated by co-axial propellers. This has been achieved through analysing the variations in power and thrust ratios as well as the effects that operating overlapping propellers in a torque balance and at equal angular velocities has on the power-plant's performance. It has also been shown that a beneficial overlap area for hovering flight exists, pointing towards the potential to increase the system's endurance. This area is present between $0 \%$ and $20 \%$ area overlap and a thrust increase of $1 \%$ has been recorded for the torque balanced setup, with a larger increase of $2 \%$ for the angular velocity balanced case, at a constant power compared to the two propellers operating in isolation. A maximum interference region between $90 \%$ and $100 \%$ (co-axial operation) has also been identified with power losses of $23 \%$ for the torque balanced case and $25 \%$ for the angular velocity balanced case at a constant thrust compared to the same power-plant with both propellers operating independently.

In conclusion, this paper summarised the performance of large scale UAV propellers operating in a tandem configuration and the gains and losses associated with this.

\section{Acknowledgement}

The authors would like to acknowledge funding contributions from both Boeing Defence UK Ltd and the Engineering and Physical Sciences Research Council (EPSRC) under grant number EP/N010523/1. Funding for the dynamometer test-rig was provided by a grant from the Northrop Grumman Foundation.

\section{References}

[1] N. Florine, An improved Helicopter, Belgium Patent Specification No. 281,721, United Kingdom Patent No. 32,832/27 (1928).

[2] W. E. Hooper, Fifty Years of Tandem Rotor Helicopter Engineering, $6^{\text {th }}$ October 1992 Cierva Memorial Lecture, Royal Aeronautical Society (London, 1992).

[3] T. A. Zientek, Cascade Rotor Blade for Low Noise, US Grant No. US7281900B2 (2005) (Available from: https://patents.google.com/patent/US7281900, accessed 09/2018)

[4] F. W. Piasecki, personal communication, V.P. Engineering, Piasecki Aircraft Corp., (Essington, 22 Sept. - 07 Oct. 2018).

[5] S. Kuznetsov, personal communication, Chief of STI Department, Yakovlev Design Bureau JSC, (Moscow, 21 Sept. -9 Oct. 2018).

[6] T. Standage, Technology Quarterly - Taking Flight. The Economist (Available from: https://www.economist.com/technologyquarterly/2017-06-08/civilian-drones

[Accessed 09/2018] 2017).

[7] L. Bollenhagen, The Bolly Book, 6 ed. (Edinburgh North: Available from: www.bolly.com.au/1998\%20Bolly\%20Book\%20v3.p df [Accessed 09/2018], 1998).

[8] J. Brandt, R. Deters, G. Ananda and M. Selig, UIUC propeller data site. (Available from: http://mselig.ae.illinois.edu/props/propDB.html. [Accessed 10/2017] 2005).

[9] I. Buchmann, Comparing the Battery with Other Power Sources. (Available from: http://batteryuniversity.com/learn/article/comparing_t he_battery_with_other_power_sources. [Accessed 04/2018] 2016).

[10] M. Miyamasu and K. Akatsu, Efficiency Comparison between Brushless DC Motor and Brushless AC Motor Considering Driving Method and Machine Design. IEEJ Journal of Industrial Applications, 2 (1) (2012) 79-86.

[11] T. J. Carroll and T. R. Carroll, Wright brothers' invention of 1903 propeller and genesis of modern propeller theory. Journal of Aircraft, 42 (1), (2005) 218-223. 
R. Dingeldein, Wind Tunnel Studies of the Performance of Multirotor Configurations. NACA TN 3236, (Washington 1954) 1-10.

[13] C. Wax and R. Tocci, Study Of The Heavy-Lift Helicopter Rotor Configuration. Boeing VERTOL ltd. (Morton, USAAVLABS 1966) 3, 44.

[14] W. Stepniewski and C. Keys, Rotary-Wing Aerodynamics. (New York. Dover Books 1979) Vol 1: 45-140, Vol 2: 182-214.

[15] J. G. Leishman, Principles of Helicopter Aerodynamics, 2 ed. (Cambridge: Cambridge University Press 2005) 1-170.

[16] R. Tapscott, Some Static Longitudinal Stability Characteristics of an Overlapped-Type Tandem-Rotor Helicopter at Low Airspeeds, NACA, TN 4393 (Langley 1958) 1-27.

[17] F. Piasecki, Tandem Rotor Helicopter, United States Patent Office, Patent No. 2,507,993 (1950) column 2, rows 21-27.

[18] J. H. McMasters and M. L. Henderson, Low-Speed Single-Element Airfoil Synthesis. NASA-SSA Third International Symposium on the Science \& Technology of Low-Speed \& Motorless Flight, (Hampton, Virginia 1979)

[19] B. Theys, G. Dimitriadis, P. Hendrick and J. De Schutter, Influence of propeller configuration on propulsion system efficiency of multi-rotor Unmanned Aerial Vehicles, International Conference on Unmanned Aircraft Systems (ICUAS), (Orlando 2016) 1064-1072.

[20] J. Lee, S. Oh, K. Yee and D. Kim, Numerical Investigation on Overlap Effects of Tandem Rotors in Forward Flight, Journal of Aeronautical and Space Sciences. Vol. 10 No. 2 (2009) 63-76.

[21] M. Brazinskas, S. D. Prior and J. P. Scanlan, An Empirical Study of Overlapping Rotor Interference for a Small Unmanned Aircraft Propulsion System, Aerospace. (2016) 1-20.

[22] M. Ramasamy, Hover Performance Measurements Towards Understanding Aerodynamic Interference in Coaxial, Tandem, and Tilt Rotors, Journal of the American Helicopter Society. (2015) 032005-1 032005-17.

[23] T-Motors, The Safest Propulsion System. (Available from: http://store-en.tmotor.com/ [Accessed 04/2018] 2003).

[24] C. P. Coleman, A Survey of Theoretical and Experimental Coaxial Rotor Aerodynamic Research, NASA, TN 3675 (Moffett Field, 1997).

[25] J. G. Leishman and M. Syal, Figure of Merit Definition for Coaxial Rotors, Journal of the American Helicopter Society. JAHS-1416-Aug-2007 (2007) 1-35.

[26] F. Harris, Twin Rotor Hover Performance. Journal of the American Helicopter Society, 44 (1) (1999) 34-37.
[27] A. Halliday and D. Cox, Wind Tunnel Experiments on a Model of a Tandem Rotor Helicopter, Ministry of Aviation Aeronautical Research Council Current Papers, C.P. No. 517 (22,103 A.R.C. Technical Report) (1961) 1-80.

[28] RCBenchmark.com (Available from: https://www.rcbenchmark.com/ [Accessed 09/2017] 2015).

[29] G. E. Sweet, Hovering Measurements for Twin-Rotor Configurations with and without Overlap, NASA, TN D-534 (Langley 1960) 1-24.

\section{Appendix}

Table A. Full-scale tandem rotorcraft data.

\begin{tabular}{|l|l|c|c|c|}
\hline \multicolumn{1}{|c|}{ Make } & \multicolumn{1}{c|}{ Model } & $\begin{array}{c}\text { First } \\
\text { Flight }\end{array}$ & $\begin{array}{c}\text { No of } \\
\text { Blades }\end{array}$ & z/D Ratio \\
\hline Piasecki & HRP-2 Rescuer & 1945 & 3 & 0.062 \\
\hline Piasecki & HUP-2 & 1948 & 3 & 0.072 \\
\hline McCulloch & MC-4 & 1948 & 3 & 0.100 \\
\hline Piasecki & H-21 Shawnee & 1952 & 3 & 0.027 \\
\hline Yakovlev & YAK-24U & 1952 & 4 & 0.089 \\
\hline Bell & HSL-1 & 1953 & 2 & 0.026 \\
\hline Piasecki & YH-16A & 1955 & 3 & 0.043 \\
\hline Boeing & CH-46E & 1958 & 3 & 0.091 \\
\hline Bristol & Belvedere-192 & 1958 & 4 & 0.111 \\
\hline Boeing & CH-47F & 1961 & 3 & 0.078 \\
\hline
\end{tabular}

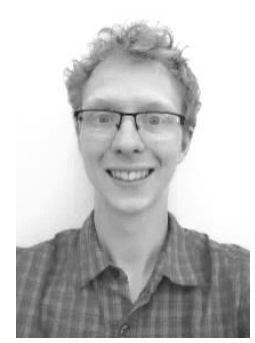

Adrian Weishäupl is an MEng student at the University of Southampton, studying Aeronautical Engineering. This research was conducted as part of his 3rd year Individual Project. This is Mr. Weishäupl's first publication. His research interests include UAV technology and aircraft design. He was an intern at the University of Southampton with SotonUAV in the summer of 2018 . He is a member of the Royal Aeronautical Society. He has represented the University of Southampton at the Farnborough Airshow 2018, as an Unmanned Systems Engineer.

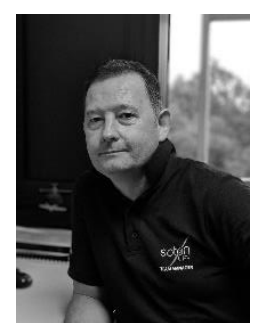

Stephen D. Prior received his B.Eng. and Ph.D. degrees from Middlesex University, in 1987 and 1992, respectively. From 1995 to 1998, he was a Senior Lecturer in Mechanical Engineering at the Tsing-Yi Technical College in Hong Kong. From 1999 to 2011, he was a Senior Lecturer, Principal Lecturer and then Reader at Middlesex University, UK. He now holds a Readership in Unmanned Air Vehicles at the University of Southampton. He is also the director of the Autonomous Systems Laboratory, which engages in defence-related research. Dr. Prior is the author of over 100 technical publications. His research interests include co-axial rotorcraft, novel UAS and perching techniques. He is an active member of the IMechE, and is a non-executive director of Tethered Drone Systems Ltd. He is on the editorial board for the Unmanned Systems Journal and the International Journal of Micro Air Vehicles. 
International Journal of Neural Systems

(C)World Scientific Publishing Company

\section{Changes for Revision 2:}

\section{Reviewer \#1:}

Major points:

1. The aim of the paper is not stated clearly. yet it is spread allover the introduction.

The aim of the paper is clearly stated in the abstract but has been strengthened and made more specific.

2. Figure 3 maybe misleading because it doesn't take into account the rapid advancement in metallurgy and production.

Figure 3 clearly states that the data is from a historical perspective and therefore does not, deliberately, mention metallurgy and production. It compares a design consideration (z/D) with performance.

3. Structure of the paper shall be stated in the end of the Introduction section for readability.

The structure has been stated at the end of the introduction.

4. While reporting experimental results, its better to show the variation side by side with the mean value, especially in Fig. 23.

Clarification has been asked on this but there has been no response. No change was made.

5. The reason of "The increase in thrust with increased interface .....semi-impermeable ground" is not convincing, it needs further justification.

Theoretical calculations have been conducted with a more substantial explanation to explain this data. This paragraph has been rewritten.

\section{Minor points:}

1. Nomenclature section shall not be enumerated.

The Nomenclature section number has been removed.

2. In Nomenclature, it is better to put one symbol for 'propeller plane separation (gap)'

$\mathrm{H}$ has been replaced with $\mathrm{z}$ when the Propeller Plane Separation is meant.

3. Paragraph 'Limited research ....' in Introduction needs to be rephrased.

"Limited research has been conducted into simulating overlapping rotors with one of few examples focusing on the forwards moving UAV with overlapping propellers [20]. This research varied the advance ratio and propeller axis and plane separation and determined that, at an advance ratio of 0.19 , normalized propeller axis separation of 0.7 (30\% propeller area overlap) and normalized propeller plane separation of 0.4 , there was no interaction between the individual propeller wakes. The distances were normalized using the propeller diameter. This means that the propellers are operating independently of each other in these conditions and thus there is no induced power loss. Unfortunately the overlap areas were only tested from $0 \%$ (no overlap) to $30 \%$."

\section{Replaced with:}

"A small number of investigations have been conducted into the simulation of overlapping forward flight rotors, one example of this was conducted by Lee et. al. [20]. This research varied the advance ratio and propeller axis and plane separation and determined that, at an advance ratio of 0.19 , normalized propeller axis separation of 0.7 (30\% propeller area overlap) and normalized propeller plane separation of 0.4 , there was no interaction between the individual propeller wakes. The distances were normalized using the propeller diameter. This means that the propellers are operating independently of each other in these conditions and thus there is no induced power loss. However, the overlap areas were only tested from $0 \%$ (no overlap) to $30 \%$ and thus make it difficult to compare." 
4. Figure 5. what is '111' ?

This was a formatting error and has been removed.

5. Mind the Figure numbering, and the first mentioned is the first listed. Figs $(7,8),(16,18)$

Figure numbering has been checked and corrected.

6. Figure 11, no need to list the 12 cases.

Figure 11 has been reduced to show 4 cases instead of 12 for increased readability.

7. some typos as: 'tilted forwardS', 'either small or positive', 'are summarise'.

'tilted forwardS' has not been found.

'either small or positive' replaced with 'either a small or positive'

'are summarise' replaced with 'are summarised'

8. no need to put '.' after the figure number.

Full stops have been removed from the figure captions.

9. First paragraph in Conclusion doesn't contribute in this section. It can be omitted.

The paragraph has been removed.

Reviewer \#3:

(1) The nomenclature need not be assigned a section number;

The Nomenclature section number has been removed.

(2) The sentences beginning with "Where ..." should be placed without indent and with the first letter in lower case "where ...".

This has been done to all the sentences beginning with "Where .."

(3) The order of placement for Figure 7 and Figure 8 should be exchanged;

This has been done.

(4) Which parts belong to "Experiment Setup" and which parts belong to "Experiment", they should be re-organized properly; The Section of Experiment should mainly present and analyze the test data.

"Experiment" section has been renamed "Results". This has been re-organised as follows:

Sections describing the propeller and apparatus (Figure 13, 14 and 15 as well as Tables 3 and 4) have been moved into the "Experimental Setup" section. This cleared up the Results section and helps to focus the reader on the important findings of this paper.

(5) So many figures are presented for the test data. They have to be organized reasonably so that the readers can easily find which are the main results and which are the supporting results, etc. The authors have to make the readers focus on their main contributions. 
The "Results" section has been cleared up by moving unnecessary data into the "Experimental Setup" section. See point 4. Unnecessary content has been moved out of the "Results" section to focus the reader on the main contributions of this paper. Figures 22-25 are the important results.

In short, the paper presents more experimental results but less analysis in the first look, which lower the academic contribution of the paper. The conclusion (not means the Section of conclusion) may not be applicable to other cases. It may be case by case. Another point, the content has to be re-organized properly. 